\title{
Performance evaluation of THz Atmospheric Limb Sounder (TALIS) of China
}

\author{
Wenyu Wang ${ }^{1,2}$, Zhenzhan Wang ${ }^{1}$, and Yongqiang Duan ${ }^{1,2}$ \\ ${ }^{1}$ Key Laboratory of Microwave Remote Sensing, National Space Science Center, \\ Chinese Academy of Sciences, Beijing, China \\ ${ }^{2}$ University of Chinese Academy of Sciences, Beijing, China
}

Correspondence: Zhenzhan Wang (wangzhenzhan@mirslab.cn)

Received: 24 May 2019 - Discussion started: 12 July 2019

Revised: 13 November 2019 - Accepted: 19 November 2019 - Published: 6 January 2020

\begin{abstract}
THz Atmospheric Limb Sounder (TALIS) is a microwave limb sounder being developed for atmospheric vertically resolved profile observations by the National Space Science Center, Chinese Academy of Sciences (NSSC, CAS). It is designed to measure temperature and chemical species such as $\mathrm{O}_{3}, \mathrm{HCl}, \mathrm{ClO}, \mathrm{N}_{2} \mathrm{O}, \mathrm{NO}, \mathrm{NO}_{2}, \mathrm{HOCl}, \mathrm{H}_{2} \mathrm{O}, \mathrm{HNO}_{3}$, $\mathrm{HCN}, \mathrm{CO}, \mathrm{SO}_{2}, \mathrm{BrO}, \mathrm{HO}_{2}, \mathrm{H}_{2} \mathrm{CO}, \mathrm{CH}_{3} \mathrm{Cl}, \mathrm{CH}_{3} \mathrm{OH}$, and $\mathrm{CH}_{3} \mathrm{CN}$ with a high vertical resolution from about 10 to $100 \mathrm{~km}$ to improve our comprehension of atmospheric chemistry and dynamics and to monitor the man-made pollution in the atmosphere. Four heterodyne radiometers including several FFT spectrometers of $2 \mathrm{GHz}$ bandwidth with $2 \mathrm{MHz}$ resolution are employed to obtain the atmospheric thermal emission in broad spectral regions centred near 118, 190, 240, and $643 \mathrm{GHz}$. A theoretical simulation is performed to estimate the retrieval precision of the main targets and to compare them with that of Aura MLS standard spectrometers. Single scan measurement and averaged measurement are considered in the simulation, respectively. The temperature profile can be obtained with a precision of $<2 \mathrm{~K}$ for a single scan from 10 to $60 \mathrm{~km}$ by using the $118 \mathrm{GHz}$ radiometer, and the 240 and $643 \mathrm{GHz}$ radiometers can provide temperature information in the upper troposphere. Chemical species such as $\mathrm{H}_{2} \mathrm{O}, \mathrm{O}_{3}$, and $\mathrm{HCl}$ show a relatively good single scan retrieval precision of $<20 \%$ over most of the useful range and $\mathrm{ClO}, \mathrm{N}_{2} \mathrm{O}$, and $\mathrm{HNO}_{3}$ can be retrieved with a precision of $<50 \%$. The other species should be retrieved by using averaged measurements because of the weak intensity and/or low abundance.
\end{abstract}

\section{Introduction}

Better precision observation of Earth's atmosphere is essential to numerical weather prediction and climate change studies. Satellites can provide daily global coverage of the atmosphere. Instruments such as nadir microwave sounders and infrared sounders have been applied to measure the atmospheric temperature and humidity but with the poor vertical resolution and altitude range (Swadley et al., 2008). Limb sounders can not only provide the temperature profile with better vertical resolution, but also gather information on chemical composition in a wide altitude range. In the terahertz domain, the measurement performances are independent of the day-night cycle. Microwave limb sounding is a particularly useful technique in detecting stratospheric and mesospheric temperature and chemistry, and also has large potential for global wind measurement in the middle and upper atmosphere (Wu et al., 2008; Baron et al., 2013).

A few instruments have been launched in the last 20 years; their observation data have offered a better understanding of the physical and chemical processes in Earth's atmosphere. The first instrument applying the microwave limb sounding technique from space was the Microwave Limb Sounder (MLS) onboard the Upper Atmosphere Research Satellite (UARS) launched in 1991. The sounder offered unique information of temperature/pressure, $\mathrm{O}_{3}, \mathrm{H}_{2} \mathrm{O}, \mathrm{ClO}$, and additional data products including $\mathrm{SO}_{2}, \mathrm{HNO}_{3}$, and $\mathrm{CH}_{3} \mathrm{CN}$ (Waters et al., 1993, 1999; Barath et al., 1993). The SubMillimetre Radiometer (SMR) onboard the Odin satellite launched in February 2001 was the first radiometer to employ sub-millimetre limb sounding. Various target species, such as $\mathrm{O}_{3}, \mathrm{ClO}, \mathrm{N}_{2} \mathrm{O}, \mathrm{HNO}_{3}, \mathrm{H}_{2} \mathrm{O}, \mathrm{CO}$, and $\mathrm{NO}$, as well as isotopes 
of $\mathrm{H}_{2} \mathrm{O}, \mathrm{O}_{3}$, and ice cloud, have been detected (Murtagh et al., 2002; Urban et al., 2005; Eriksson et al., 2007). The Aura MLS, the successor of the UARS MLS onboard the Aura satellite launched in July 2004, gave successful observations of $\mathrm{OH}, \mathrm{HO}_{2}, \mathrm{H}_{2} \mathrm{O}, \mathrm{O}_{3}, \mathrm{HCl}, \mathrm{ClO}, \mathrm{HOCl}, \mathrm{BrO}$, $\mathrm{HNO}_{3}, \mathrm{~N}_{2} \mathrm{O}, \mathrm{CO}, \mathrm{HCN}, \mathrm{CH}_{3} \mathrm{CN}, \mathrm{SO}_{2}$, ice cloud, and wind (Waters et al., 2004, 2006; Wu et al., 2008; Livesey et al., 2013). The Superconducting Submillimeter-wave LimbEmission Sounder (SMILES) onboard the Japanese Experiment Module (JEM) of the International Space Station (ISS) launched in September 2009 (Kikuchi et al., 2010). SMILES was equipped with $4 \mathrm{~K}$ cooled superconductor-insulatorsuperconductor (SIS) mixers to reduce the system noise temperature, so that the sensitivity of SMILES was higher than that of other similar sensors such as MLS and SMR (Takahashi et al., 2010; Baron et al., 2011). Currently, several new instruments are being developed. Stratospheric Inferred Winds (SIW) is a Swedish mini sub-millimetre limb sounder for measuring wind, temperature, and molecules in the stratosphere. It can provide horizontal wind vectors within 30$90 \mathrm{~km}$, as well as the profiles of temperature, $\mathrm{O}_{3}, \mathrm{H}_{2} \mathrm{O}$, and other trace chemical species (Baron et al., 2018). SIW is designed for small satellites and will be launched as early as 2020-2022. In addition, the successor of SMILES, SMILES2 , is being studied for measuring the whole vertical range of 15-180 km with low noise (Ochiai et al., 2017).

$\mathrm{THz}$ Atmospheric Limb Sounder (TALIS) is the preresearch project of civil aerospace technology proposed by the China National Space Administration (CNSA). TALIS is being designed at the National Space Science Center, Chinese Academy of Sciences (NSSC, CAS), for good precision measurement of atmospheric temperature and key chemical species. It has four microwave radiometers in the frequency bands of $118,190,240$, and $643 \mathrm{GHz}$, which are similar to the Aura MLS. The TALIS mission objectives are to provide the information for research on the dynamics and the chemistry of the middle and upper atmosphere by measuring the volume mixing ratio (VMR) profile of the chemical species and other atmospheric conditions such as cirrus with much finer spectral resolution. The pre-research will be completed in 2020 and a prototype will be tested. The satellite mission equipped with TALIS will be proposed around 2021.

In this paper, we present a simulation study on precision estimates for the geophysical parameters measured by TALIS. The outline of the present study is as follows: Sect. 2 describes the instrument characteristics and spectral bands. The retrieval method and the simulation result are discussed in Sects. 3 and 4, respectively. The final section gives a conclusion about the performance and future works.
Table 1. Characteristics of the TALIS payload.

\begin{tabular}{ll}
\hline Satellite altitude & $600 \mathrm{~km}$ \\
\hline Vertical scan altitude & $0-100 \mathrm{~km}$ \\
\hline LOS nadir angle & $66.07-68.17^{\circ}\left(2.1^{\circ}\right)$ \\
\hline Scan velocity & $0.21^{\circ} \mathrm{s}^{-1}\left(36 \mathrm{~s} \mathrm{scan}^{-1}\right)$ \\
\hline Spectrum integration time & $0.1 \mathrm{~s}(1 \mathrm{~km})$ \\
\hline Antenna size & $1.6 \mathrm{~m}$ \\
\hline Antenna vertical FOV & $5.5,3.8,3.3,0.96 \mathrm{~km}$ \\
\hline Spectrometer bandwidth & $2 \mathrm{GHz}$ \\
\hline Spectrometer resolution & $2 \mathrm{MHz}$ \\
\hline LO frequency & $120,190.1,239.66$, \\
\hline
\end{tabular}

\section{Instrument overview}

\subsection{Instrument characteristics}

The TALIS payload (Fig. 1) and its proposed scan characteristics are summarised in Table 1. The instrument will be set at a Sun-synchronous orbit at a normal altitude of $600 \mathrm{~km}$. The offset parabolic antenna is made of a single reflector with a $1.6 \mathrm{~m}$ projective aperture and four independent feeds. The layout of four discrete feeds is shown in Fig. 2. Compared with the quasi-optical separation layout (such as MLS), this strategy is easier and has better observation precision since it needs fewer reflectors. But it will lead to a vertical observed displacement of about $20 \mathrm{~km}$ between 118, 190, and $643 \mathrm{GHz}$ and a horizontal displacement of $240 \mathrm{GHz}$. The widths of the field of view (FOV) at the tangent point are about 5.5, 3.8, 3.3 , and $0.96 \mathrm{~km}$ at $118,190,240$, and $643 \mathrm{GHz}$, respectively. The two-point calibration method is adopted by TALIS, and two calibration targets are set at the end of the arm. The extra target can be used to improve the calibration precision and evaluate the antenna effect and non-linearity. At the beginning of the scan, TALIS will view the hot target (ambient temperature) and the extra target (lower temperature) in $3 \mathrm{~s}$, and then it will scan the limb from 0 to $100 \mathrm{~km}$ vertically and obtain the spectra every $1 \mathrm{~km}$ with an integration time of $0.1 \mathrm{~s}$; finally, it views the cold space at $200 \mathrm{~km}$ in $5 \mathrm{~s}$. The process of retrace is the same (also records data) and gives a total period (scan and retrace) of about $36 \mathrm{~s}$.

TALIS has four radiometers which cover the significant thermal emission spectra in the $118,190,240$, and $643 \mathrm{GHz}$ regions (see Table 2). Single-sideband (SSB) can keep the complete spectral lines, while double-sideband (DSB) can cover more spectral lines because of the image band. Thus, all the radiometers of TALIS will operate in the doublesideband mode except the $118 \mathrm{GHz}$ radiometer. Eleven FFT spectrometers of $2 \mathrm{GHz}$ bandwidth with $2 \mathrm{MHz}$ resolution 

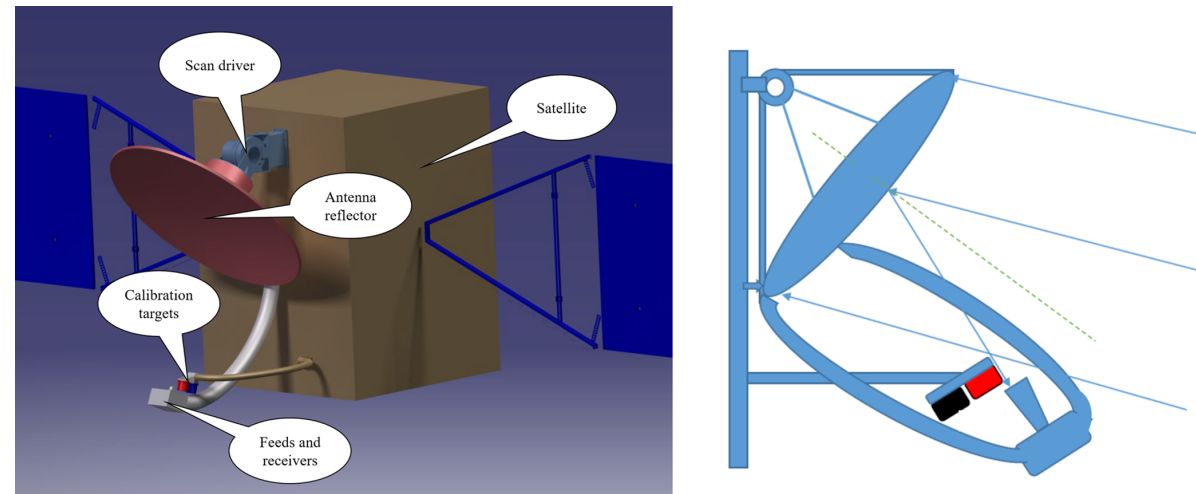

Figure 1. Schematic diagram of the TALIS payload. The reflector, feeds, and receivers are formed into a whole. The scan driver controls the scan angle. The calibration system is fixed in the satellite. At the beginning, the feeds are covered by calibration targets. Then it will scan the limb. When the system rotates to the top, it will view the cold space.

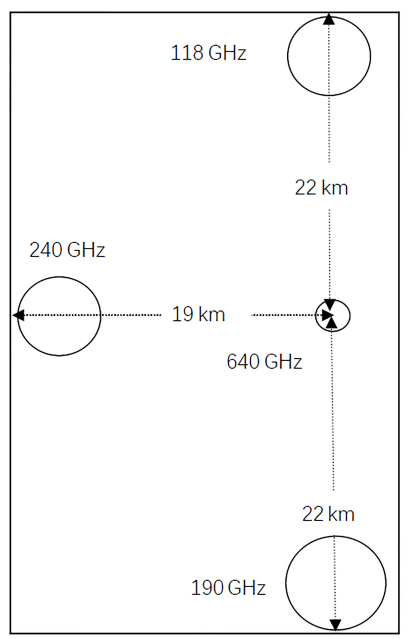

Figure 2. The layout of the four antenna feeds. The observation displacements of the four radiometers are shown.

will be used in TALIS. The bands and system noise temperature for each radiometer are shown in Table 2 .

\subsection{Spectral bands}

The spectral bands of TALIS are selected with the following criteria: (1) maximisation of the number of species which will exert a strong influence on atmospheric chemistry and dynamics, (2) necessary space between the passband, and (3) trade-off between realisable bandwidth and resolution. TALIS covers most spectral bands of the Aura MLS and extends them (see Fig. 3), but lacks the $2.4 \mathrm{THz}$ band. The broader bandwidth and the finer resolution of TALIS can provide a better retrieval precision and effective altitude range compared with the Aura MLS. More chemical species can be measured by TALIS, such as $\mathrm{NO}_{2}, \mathrm{NO}$, and $\mathrm{SO}_{2}$ (normal concentration).
The $118 \mathrm{GHz}$ radiometer, covering the strong $\mathrm{O}_{2}$ line at $118.75 \mathrm{GHz}$, is used to measure the atmospheric temperature and tangent pressure. Since there are few meteorological data set about the temperature above the middle atmosphere with good vertical resolution, it is necessary to measure the temperature profile with a wide altitude range, good vertical resolution, and good precision. In addition, the Zeeman effect will affect the $\mathrm{O}_{2}$ line, and the influence should be studied (Schwartz et al., 2006). Other information such as ice cloud can be treated as an additional measurement. Figure 4 gives an overview of the $118 \mathrm{GHz}$ spectral band.

The $190 \mathrm{GHz}$ radiometer is mainly designed to cover the $183.31 \mathrm{GHz} \mathrm{H}_{2} \mathrm{O}$ line. Monitoring water vapour is important for understanding the mechanisms of humidity feedback on climate and is essential for improving the accuracy of the weather forecast. Other chemical species such as $\mathrm{N}_{2} \mathrm{O}$, $\mathrm{ClO}, \mathrm{O}_{3}$, and $\mathrm{HCN}$ are also included in $190 \mathrm{GHz}$ bands (see Fig. 5).

The main objective of the $240 \mathrm{GHz}$ radiometer is to measure the $\mathrm{CO}$ at $230.54 \mathrm{GHz}$, and the strong $\mathrm{O}_{3}$ lines in a wide spectral band where upper tropospheric $\mathrm{O}_{3}$ can be obtained with good precision because of the weak water vapour continuum absorption. In addition, the $233.95 \mathrm{GHz} \mathrm{O}_{2}$ line will be used to measure temperature and tangent pressure together with the $118.75 \mathrm{GHz}$ line. $\mathrm{SO}_{2}$ is an important pollutant in the Earth' atmosphere and will give rise to acid rain. There is no obvious $\mathrm{SO}_{2}$ emission with the standard profile present in the passband of the $240 \mathrm{GHz}$ radiometer. The only $\mathrm{SO}_{2}$ which is observable by the MLS comes from volcanic eruptions. The MLS demonstrated that $\mathrm{SO}_{2}$ can be measured by 190, 240, and $640 \mathrm{GHz}$ radiometers, but only the $240 \mathrm{GHz}$ $\mathrm{SO}_{2}$ product is recommended for general use (Pumphrey et al., 2015). The wide and strong lines of $\mathrm{HNO}_{3}$ can be used to retrieve profiles well. $\mathrm{NO}_{2}$ is a unique species not covered by the Aura MLS, and TALIS' wider bandwidth and finer resolution have the potential ability to measure it. The spectra of the $240 \mathrm{GHz}$ radiometer are depicted in Fig. 6. 
Table 2. Spectral bands and Tsys of TALIS.

\begin{tabular}{|c|c|c|c|c|c|c|c|}
\hline Radiometer & $\begin{array}{l}\text { TALIS } \\
(\mathrm{GHz})\end{array}$ & $\begin{array}{l}\text { Tsys* for } \\
\text { TALIS }\end{array}$ & $\begin{array}{l}\text { Tsys for } \\
\text { MLS }\end{array}$ & Radiometer & $\begin{array}{l}\text { TALIS } \\
(\mathrm{GHz})\end{array}$ & $\begin{array}{l}\text { Tsys for } \\
\text { TALIS }\end{array}$ & $\begin{array}{l}\text { Tsys for } \\
\text { MLS }\end{array}$ \\
\hline $118 \mathrm{GHz}$ & $117.75-119.75$ & $1000 \mathrm{~K}$ & $1200 \mathrm{~K}$ & \multirow[t]{3}{*}{$240 \mathrm{GHz}$} & $\begin{array}{l}229.66-231.66 \\
247.66-249.66\end{array}$ & \multirow[t]{3}{*}{$1000 \mathrm{~K}$} & \multirow[t]{3}{*}{$1200-1600 \mathrm{~K}$} \\
\hline \multirow[t]{6}{*}{$190 \mathrm{GHz}$} & $\begin{array}{l}175.5-177.5 \\
202.7-204.7\end{array}$ & \multirow[t]{6}{*}{$1000 \mathrm{~K}$} & \multirow[t]{6}{*}{$900-1100 \mathrm{~K}$} & & $\begin{array}{l}232.16-234.16 \\
245.16-247.16\end{array}$ & & \\
\hline & $\begin{array}{l}178.9-180.9 \\
199.3-201.3\end{array}$ & & & & $\begin{array}{l}234.66-236.66 \\
242.66-244.66\end{array}$ & & \\
\hline & $\begin{array}{l}183.0-185.0 \\
195.2-197.2\end{array}$ & & & \multirow[t]{4}{*}{$643 \mathrm{GHz}$} & $\begin{array}{l}624.47-626.47 \\
659.27-661.27\end{array}$ & \multirow[t]{4}{*}{$2300 \mathrm{~K}$} & \multirow[t]{4}{*}{$4000-4400 \mathrm{~K}$} \\
\hline & & & & & $\begin{array}{l}627.37-629.37 \\
656.37-658.37\end{array}$ & & \\
\hline & & & & & $\begin{array}{l}632.37-634.37 \\
651.37-653.37\end{array}$ & & \\
\hline & & & & & $\begin{array}{l}634.87-636.87 \\
648.87-650.87\end{array}$ & & \\
\hline
\end{tabular}

* This is a single-sideband value for the $118 \mathrm{GHz}$ radiometer, and the double-sideband value is for the other radiometers.
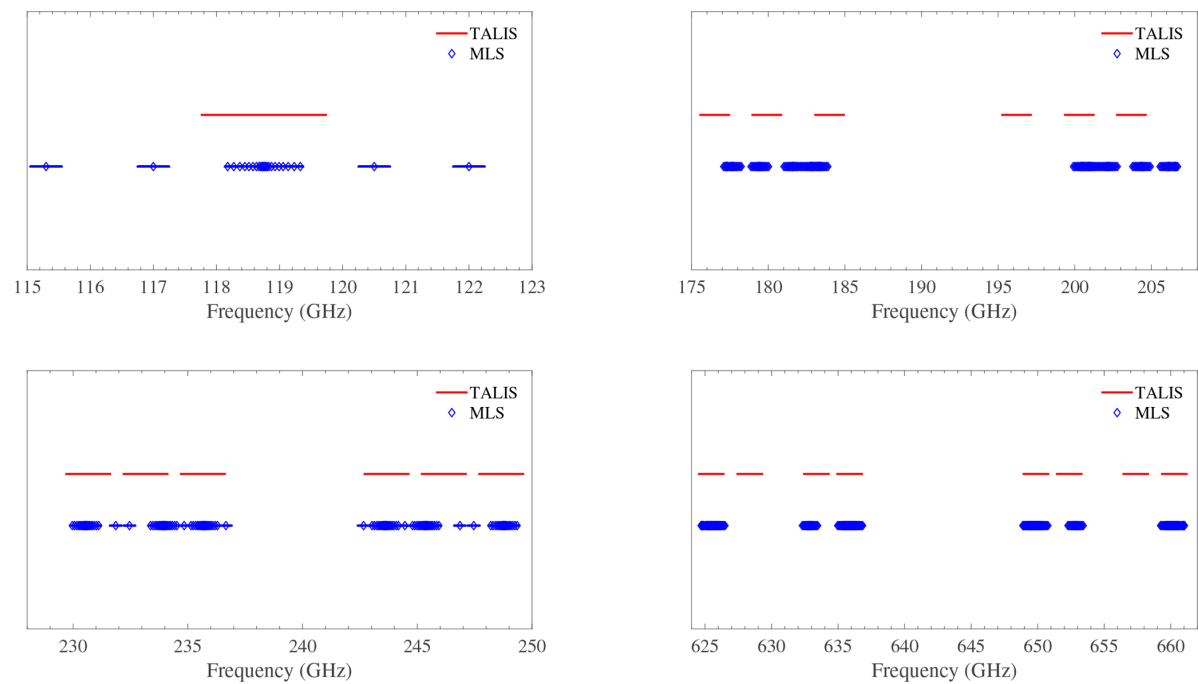

Figure 3. Spectral bands of the Aura MLS and TALIS radiometers. The diamonds represent the filter centres and the solid lines mean the bandwidth of the MLS.

The $643 \mathrm{GHz}$ radiometer is designed to cover as many spectral lines as possible; thus, about 17 species are included. The spectral lines covering $\mathrm{O}_{3}, \mathrm{HCl}, \mathrm{ClO}, \mathrm{N}_{2} \mathrm{O}, \mathrm{O}_{2}$, and $\mathrm{H}_{2} \mathrm{O}$ are clearly visible (Fig. 7), and other lines which are relatively weak such as $\mathrm{NO}, \mathrm{HNO}_{3}, \mathrm{CO}, \mathrm{SO}_{2}, \mathrm{BrO}, \mathrm{HO}_{2}$, $\mathrm{H}_{2} \mathrm{CO}, \mathrm{HOCl}$, and $\mathrm{CH}_{3} \mathrm{Cl}$ can also be used. The $\mathrm{O}_{2}$ line at $627.75 \mathrm{GHz}$ and the $\mathrm{H}_{2} \mathrm{O}$ line at $657.9 \mathrm{GHz}$ have the potential to be used as supplements to the 118 and $190 \mathrm{GHz}$ radiometers. $\mathrm{O}_{3}$ is the major species in the stratosphere and mesosphere, which is quite important in atmospheric radiation transfer. Using the high sensitivity lines in the $643 \mathrm{GHz}$ bands, one can measure $\mathrm{O}_{3}$ with good precision (Takahashi et al., 2011; Kasai et al., 2013). The only lines of $\mathrm{HCl}$ below $1 \mathrm{THz}$ are in the $625 \mathrm{GHz}$ frequency band; thus, $\mathrm{HCl}$ can be measured by the $643 \mathrm{GHz}$ radiometer (Lary and Aulov, 2008). $\mathrm{ClO}$ is a key catalyst for ozone loss and the $649.45 \mathrm{GHz}$ line is suitable for $\mathrm{ClO}$ observation with good precision (Santee et al., 2008; Sato et al., 2012). The HOCl, which will affect the stratospheric chlorine budget, has distinct lines above $600 \mathrm{GHz}$, and the $635.87 \mathrm{GHz}$ line has been pointed out to be the best line for observation (Urban, 2003). Both the 649.701 and $660.486 \mathrm{GHz}$ lines can be used to mea- 


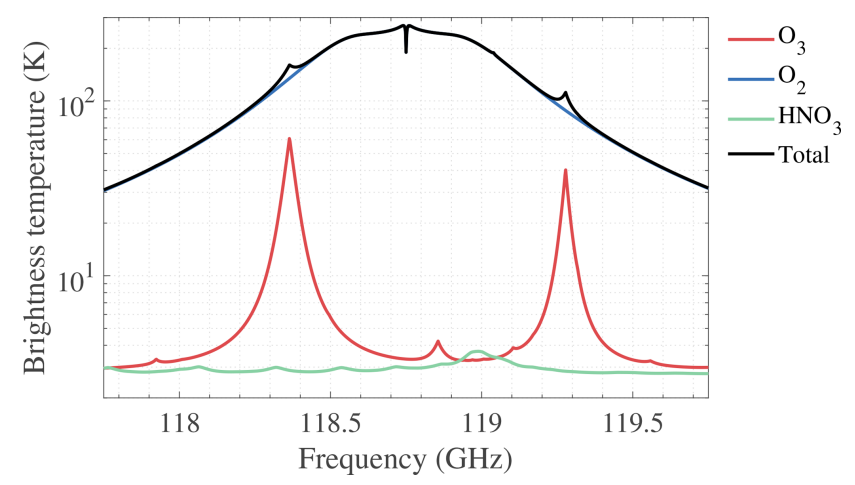

Figure 4. Contributions of the main target chemical species to the $118 \mathrm{GHz}$ spectrum. The brightness temperature is measured from the single-sideband radiometer. The tangent height is $30 \mathrm{~km}$.

sure the hydroperoxyl radical $\mathrm{HO}_{2}$, which will contribute to the catalytic ozone chemistry in the upper stratosphere and mesosphere (Millán et al., 2015). Since $\mathrm{ClO}, \mathrm{HO}_{2}$, and $\mathrm{HOCl}$ all can be measured, the reaction rate of $\mathrm{ClO}$ and $\mathrm{HO}_{2}$ to form $\mathrm{HOCl}$ in the atmosphere can be determined (Johnson et al., 1995). $\mathrm{N}_{2} \mathrm{O}$ can be measured at $652.834 \mathrm{GHz}$, which has been validated by the MLS (Lambert et al., 2007). NO has two weak signals at 651.45 and $651.75 \mathrm{GHz}$, which can be used to measure the abundance. $\mathrm{HNO}_{3}$ can be measured using the $650 \mathrm{GHz}$ bands. Measuring these nitrogen species will help researchers to understand the chemistry and dynamics of the atmosphere better. The $\mathrm{BrO}$, which plays an important role in the depletion of ozone, can be measured using the 624.768 and $650.179 \mathrm{GHz}$ lines. Because of the low abundance of $\mathrm{BrO}$, measurements must be significantly averaged in order to get reliable results (Millán et al., 2012). $\mathrm{CO}$ and $\mathrm{H}_{2} \mathrm{CO}$ are the major species in the $\mathrm{CH}_{4}$ oxidation to $\mathrm{CO}_{2}$ and $\mathrm{H}_{2} \mathrm{O}$ in the stratosphere and mesosphere (Suzuki et al., 2015). The major spectral line of $\mathrm{CO}$ used by the MLS is at $230.538 \mathrm{GHz}$; however, the $661.07 \mathrm{GHz}$ line can also provide information (Livesey et al., 2008). $\mathrm{H}_{2} \mathrm{CO}$ has a line at $656.45 \mathrm{GHz}$, but the signal is very weak. The $\mathrm{SO}_{2}$ lines in the $660 \mathrm{GHz}$ band have the potential to detect the background levels of $\mathrm{SO}_{2} \cdot \mathrm{CH}_{3} \mathrm{Cl}$ can be measured in the $649 \mathrm{GHz}$ band near the line of ClO. The MLS measured $\mathrm{CH}_{3} \mathrm{OH}$ and $\mathrm{CH}_{3} \mathrm{CN}$ in the troposphere and lower stratosphere by the $625 \mathrm{GHz}$ spectrometer (Pumphrey et al., 2011).

\section{Retrieval methodology}

\subsection{Forward model}

The retrieval of data measured by the microwave limb sounder requires the accurate simulation of the observed thermal emission spectra. The forward model is a mathematical tool used to describe the radiative transfer, spectroscopy, and instrumental characteristics. The output of the forward model is the convolution of the atmospheric radiation and instrument response.

Radiative transfer describes the emission, propagation, scattering, and absorption of electromagnetic radiation (Mätzler, 2006). Scattering can usually be neglected above the upper troposphere as the atmosphere is largely cloud-free at these altitudes, and such clouds as there are (e.g. polar stratospheric clouds) have particle sizes shorter than the TALIS observation wavelengths. In this way and assuming local thermodynamic equilibrium (LTE), the formal solution of the radiative transfer equation is defined by

$$
\begin{aligned}
& I_{v}\left(S_{2}\right)=I_{v}\left(S_{1}\right) e^{-\tau_{v}\left(S_{1}, S_{2}\right)} \\
& \quad+\int_{S_{1}}^{S_{2}} \alpha_{v}(s) B_{v}(T) e^{-\tau_{v}\left(S, S_{2}\right)} \mathrm{d} s,
\end{aligned}
$$

where $I_{v}$ is the radiance at frequency $v$ reaching the sensor, $\alpha$ is the absorption coefficient, and $\tau$ is the opacity or optical thickness. $B_{v}$ stands for the atmospheric emission which is given by the Planck function describing the radiation of a black body at temperature $T$ and frequency $v$ per unit solid angle, unit frequency interval, and unit emitting surface (Urban et al., 2004):

$$
B_{v}(T)=\frac{2 h v^{3}}{c^{2}} \frac{1}{e^{h v / k_{B} T}-1},
$$

where $h$ is the Planck constant, $c$ is the speed of light, and $k_{B}$ denotes the Boltzmann constant.

Spectroscopy models and databases allow us to compute the absorption coefficient, which requires pressure, temperature, and the species concentrations along the line of sight. The basic expression can be written as

$\alpha(v)=n S(T) F(v)$,

where $S$ is called the line strength, $F$ means the line shape function, and $n$ is the number density of the absorber.

Sensor characteristics also have to be taken into account by the forward model, including the antenna field of view, the sideband folding, and the spectrometer channel response (Eriksson et al., 2006).

Firstly, the radiance which encounters the antenna response could be expressed by the integration:

$I_{v}^{\mathrm{a}}=\int_{\Omega} I_{v}(\Omega) W_{v}^{\mathrm{a}}(\Omega) \mathrm{d} \Omega$,

where $W_{v}^{\mathrm{a}}$ is the normalised antenna response function. Normally, the variation of $I_{v}$ in the azimuth angle dimension can be neglected or calculated beforehand. Secondly, a heterodyne mixer converts the signals to intermediate frequency, folding the upper and lower sideband signals together in consequence. The apparent intensity after the mixer can be modelled as

$I_{v}^{\mathrm{if}}=\frac{W_{v}^{\mathrm{s}}(v) I_{v}^{\mathrm{a}}+W_{v}^{\mathrm{s}}\left(v^{\prime}\right) I_{v^{\prime}}^{\mathrm{a}}}{W_{v}^{\mathrm{s}}(v)+W_{v}^{\mathrm{s}}\left(v^{\prime}\right)}$ 

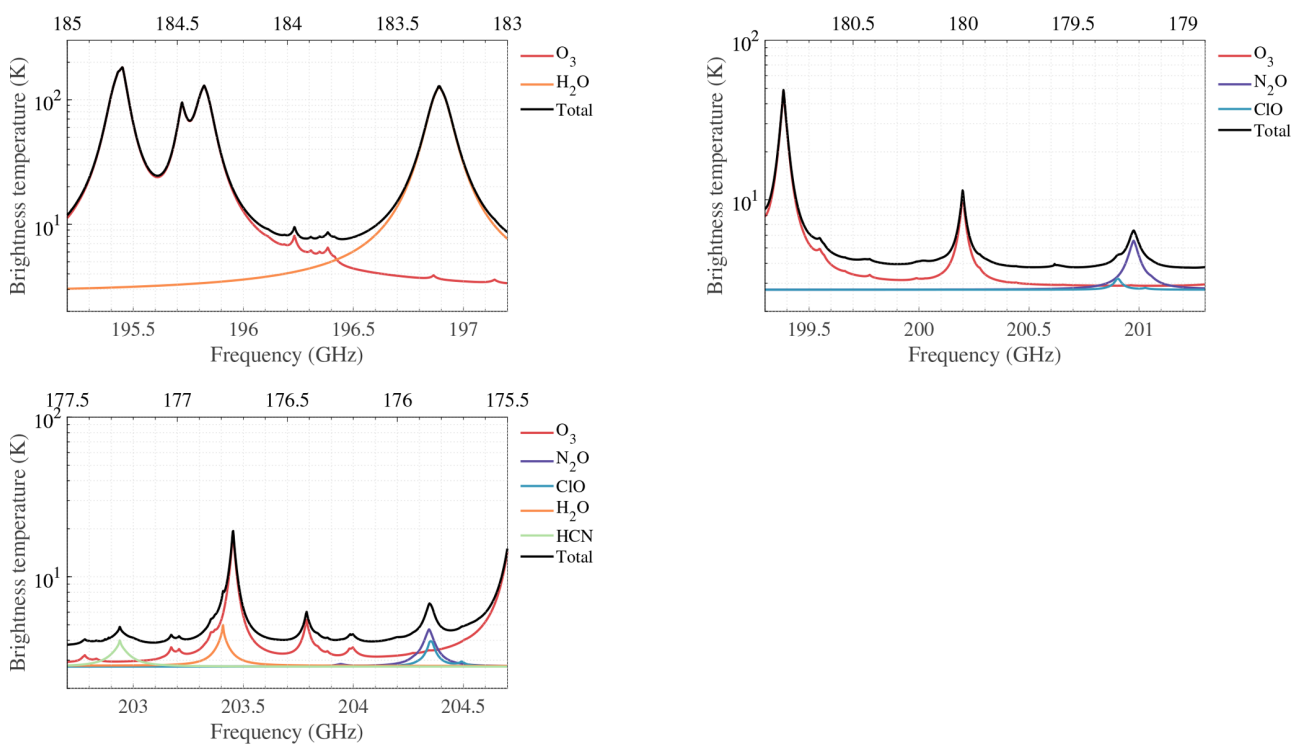

Figure 5. Contributions of the main target chemical species to the $190 \mathrm{GHz}$ spectra. The brightness temperature is measured from the doublesideband radiometer. The tangent height is $30 \mathrm{~km}$. The top axis represents the lower sideband frequencies and the bottom axis represents the upper sideband frequencies. Each panel represents a single spectrometer.
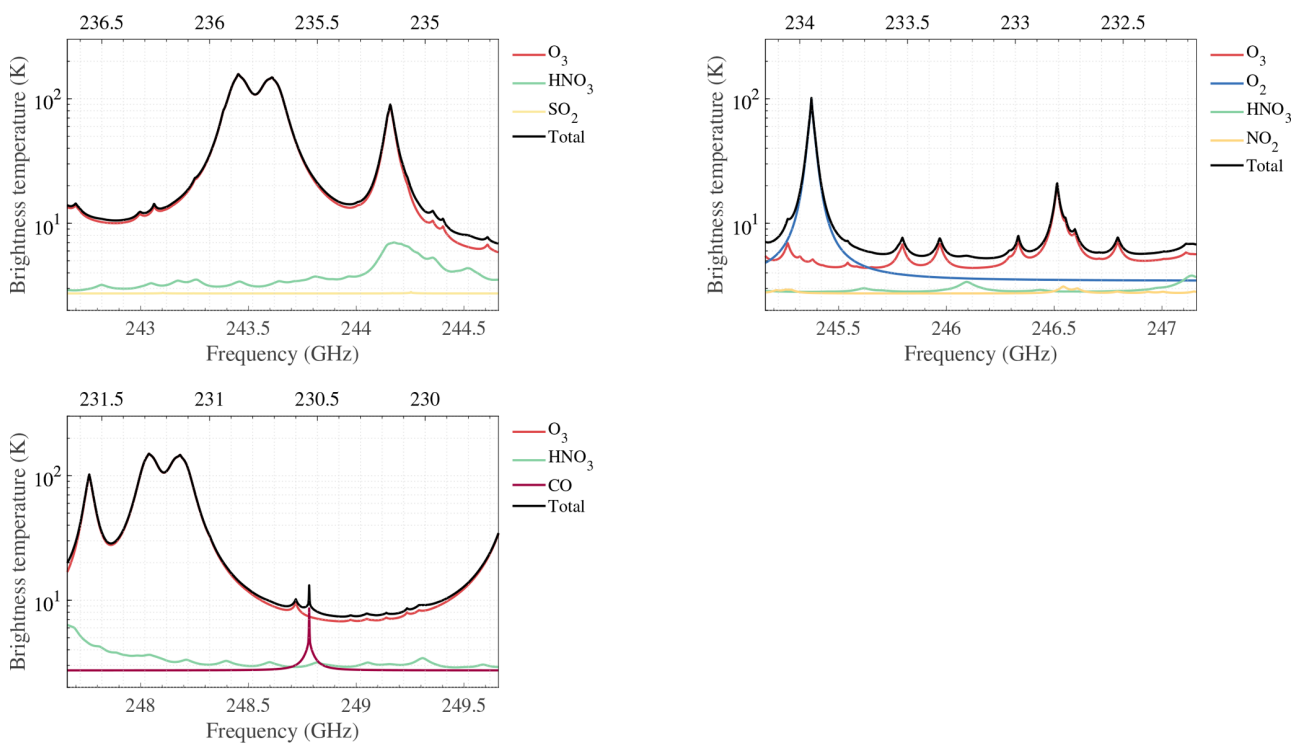

Figure 6. Contributions of the main target chemical species to the $240 \mathrm{GHz}$ spectra. The brightness temperature is measured from the doublesideband radiometer. The tangent height is $30 \mathrm{~km}$. The top axis represents the lower sideband frequencies and the bottom axis represents the upper sideband frequencies. Each panel represents a single spectrometer.

where $W_{v}^{\mathrm{s}}$ means the sideband response. At last, the final signal will be recorded by spectrometers, which can be described in a similar way to the antenna response:

$I^{\mathrm{c}}=\int_{v} I_{v}^{\mathrm{if}} W_{v}^{\mathrm{c}}(v) \mathrm{d} v$

Here $W_{v}^{\mathrm{c}}$ means the normalised channel response, and the radiance is denoted $I^{\mathrm{c}}$.
The measured radiance is transformed to brightness temperatures using the Planck function.

\subsection{Retrieval algorithm}

The optimal estimation method (OEM) is the most common method used in atmospheric sounding for retrieving vertical profiles of chemistry species (Rodgers, 2000). 

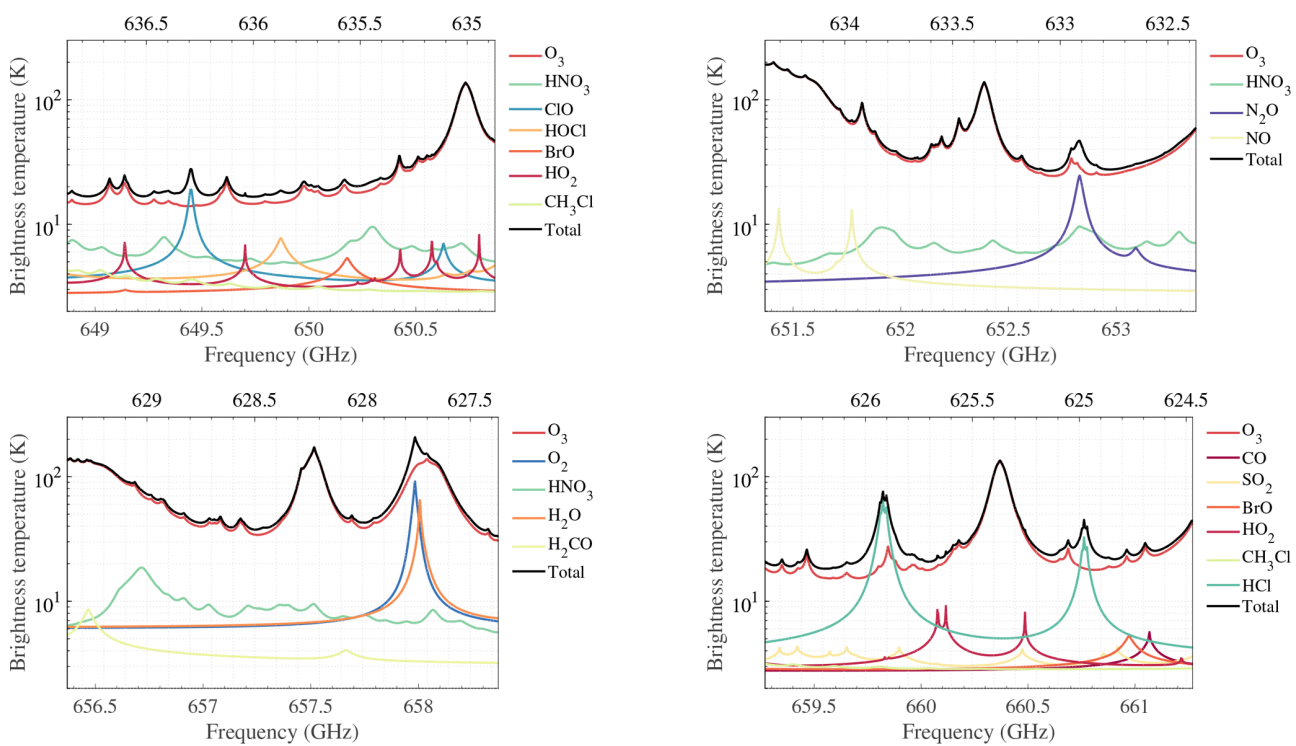

Figure 7. Contributions of the main target chemical species to the $643 \mathrm{GHz}$ spectra. The brightness temperature is measured from the doublesideband radiometer. The tangent height is $30 \mathrm{~km}$. The top axis represents the lower sideband frequencies and the bottom axis represents the upper sideband frequencies. Each panel represents a single spectrometer.

In OEM theory, a predicted noisy measurement $\hat{y}$ can be expressed by a forward model $\boldsymbol{F}$ with an unknown atmospheric state $\boldsymbol{x}$ and the system noise $\epsilon_{y}$ according to

$\hat{y}=\boldsymbol{F}(\boldsymbol{x}, \boldsymbol{b})+\epsilon_{y}$.

The noiseless predicted radiances $\boldsymbol{F}(\boldsymbol{x}, \boldsymbol{b})$ are compared with the observed radiance $y$ so that the unknown state which minimises the cost function $\chi^{2}$ could be found. The cost function is given by

$$
\begin{aligned}
& \chi^{2}=[y-\mathbf{F}(\boldsymbol{x}, \mathbf{b})]^{T} \mathbf{S}_{y}^{-1}[\boldsymbol{y}-\mathbf{F}(\boldsymbol{x}, \boldsymbol{b})] \\
& +\left[\boldsymbol{x}-\boldsymbol{x}_{\mathrm{a}}\right]^{T} \mathbf{S}_{\mathrm{a}}^{-1}\left[\boldsymbol{x}-\boldsymbol{x}_{\mathrm{a}}\right],
\end{aligned}
$$

where $\boldsymbol{x}_{\mathrm{a}}$ is an a priori state vector, and $\mathbf{S}_{\mathrm{a}}$ and $\mathbf{S}_{y}$ stand for the covariance matrices representing the natural variability of the state vector and the measurement error vector, respectively. Assuming there is no correlation between the channels, the off-diagonal elements of $\mathbf{S}_{y}$ are zero and the diagonal elements are set to the square of the system noise. Usually, a simple formula can be used to determine the SSB radiometric noise standard deviation:

$\epsilon=\frac{T_{\text {sys }}}{\sqrt{\beta d \tau}}$,

where $T_{\text {sys }}$ is the system noise temperature, which is the sum of the receiver noise temperature and the atmospheric temperature received by the antenna, $\beta$ is the noise-equivalent bandwidth, and $d \tau$ is the integration time for measuring a single spectrum. The diagonal elements of $\mathbf{S}_{\mathrm{a}}$ specify a priori variance and the off-diagonal terms are used to describe correlations between adjacent elements in order to make the re- trieved profile smoother. The Planck function is used to compute the brightness temperature.

Finally, the Levenberg-Marquardt method, which is the modification of the Gauss-Newton iterative, is used to solve the non-linear problem. The solution is given by

$$
\begin{gathered}
\boldsymbol{x}_{i+1}=\boldsymbol{x}_{i}+\left[(\mathbf{I}+\gamma) \mathbf{S}_{\mathrm{a}}^{-1}+\mathbf{K}_{\mathrm{xi}}^{T} \mathbf{S}_{y}^{-1} \mathbf{K}_{i}\right]^{-1} \\
\left\{\mathbf{K}_{\mathrm{xi}}^{T} \mathbf{S}_{y}^{-1}\left[\boldsymbol{y}-\mathbf{F}\left(\boldsymbol{x}_{i}\right)\right]-\mathbf{S}_{\mathrm{a}}^{-1}\left(\boldsymbol{x}_{i}-\boldsymbol{x}_{\mathrm{a}}\right)\right\},
\end{gathered}
$$

where $\gamma$ denotes the Levenberg-Marquardt parameter and $\mathbf{K}_{\mathrm{x}_{\mathrm{i}}}$ represents the weighting function matrix (Jacobian). I represents the identity matrix.

The OEM provides an approach to describe the retrieval error completely. The averaging kernel matrix $\mathbf{A}$, which represents the sensitivity of the retrieved state to the true state, is written as

$\mathbf{A}=\mathbf{G}_{y} \mathbf{K}_{x}=\frac{\partial \hat{x}}{\partial \boldsymbol{x}}$,

where $\mathbf{G}_{y}$ is the contribution matrix, which expresses the sensitivity of the retrieved state to the measurement:

$\mathbf{G}_{y}=\frac{\partial \hat{x}}{\partial \mathbf{y}}=\left(\mathbf{K}_{x}^{T} \mathbf{S}_{y} \mathbf{K}_{x}+\mathbf{S}_{\mathrm{a}}^{-1}\right)^{-1} \mathbf{K}_{x}^{T} \mathbf{S}_{y}^{-1}$.

The retrieval resolution can be estimated from the full width at half maximum (FWHM) of the averaging kernel (Marks and Rodgers, 1993).

There is another useful variable defined as the measurement response, which represents the true state contribution in the retrieval (Baron et al., 2002):

$W(i)=\sum_{j}|A(i, j)|$. 
The ideal measurement response should be near 1 . In practice, the reliable range of a retrieval is usually characterised by $|W-1|<0.2$.

The retrieval error can be described by two covariance matrices, the smoothing error covariance matrix which is from the need for a priori information,

$\mathbf{S}_{n}=(\mathbf{A}-\mathbf{I}) \mathbf{S}_{\mathrm{a}}(\mathbf{A}-\mathbf{I})^{T}$,

and the measurement error covariance matrix due to the measurement noise,

$\mathbf{S}_{m}=\mathbf{G}_{y} \mathbf{S}_{y} \mathbf{G}_{y}^{T}$.

The error covariance matrix used in the following simulation is the total of $\mathbf{S}_{n}$ and $\mathbf{S}_{m}$.

\section{Measurement performance}

\subsection{Simulation setup}

The objective of the simulation is to evaluate the observation performance of TALIS. In this simulation, the Atmospheric Radiative Transfer Simulator (ARTS 2.3) forward model and its corresponding retrieval tool, Qpack2, are used (Eriksson et al., 2005, 2011). The instrumental setup follows the characteristics of TALIS described in Tables 1 and 2. The ideal rectangle back-end channel response function is used. The simulation antenna patterns of the four radiometers are shown in Fig. 8. The full-width at half-power points of antenna patterns are used in the following simulation.

In this simulation, the scan altitude range is from 10 to $90 \mathrm{~km}$ and the spectra are obtained every $1 \mathrm{~km}$. A retrieval grid with $2.5 \mathrm{~km}$ spacing is used since it can match the FOV of TALIS well, and cutting down the size of the state vector will give a significant increase in speed (Livesey and Van Snyder, 2004). A mid-latitude summer atmospheric condition extracted from FASCOD which is provided by ARTS (profiles of $\mathrm{BrO}$ and $\mathrm{HO}_{2}$ are from MLS L3 v4.2 monthly averaged data, $20-30^{\circ} \mathrm{N}$, July 2018 ) is chosen to perform the simulation (Clough et al., 1986). The scattering from tropospheric clouds, refraction, and the Zeeman effect are not considered because of the large computational complexity. A spectroscopic line parameters catalogue created with the data taken from the JPL catalogue (Pickett et al., 1998), HITRAN database (Rothman et al., 2013), and Perrin catalogue (Perrin et al., 2005) is used for line-by-line absorption calculation. The measurement covariance matrix is set diagonal as described in Sect. 3 in order to reduce the computing time; $110 \%$ of a typical profile is used to build the a priori covariance matrix with $3 \mathrm{~km}$ vertical correlation between the adjacent pressure levels by a parametric exponential function. The true profiles are defined with a vertical resolution of $0.5 \mathrm{~km}$. The true species profiles are multiplied by a factor of 1.1 to be the a priori profiles, and to the true temperature profile is added a $5 \mathrm{~K}$ offset to be the a priori profile. The molecules are retrieved simultaneously from each band. No spectrally flat extinction term was added.

The expected $1 \sigma$ noise is calculated by Eq. (9), and the noise is assumed to be $2.2,2.2,2.2$, and $5.1 \mathrm{~K}$ at 118,190 , 240 , and $640 \mathrm{GHz}$, respectively. The species such as $\mathrm{BrO}$ and $\mathrm{HO}_{2}$ whose emission radiances are small compared with the system noise must be averaged to increase the precision. Here the lower noise ( $1 \sigma$ noise multiplied by a factor of 0.1 , equivalent to a $10^{\circ}$ latitude weekly zonal mean) is used to represent the averaged production.

\subsection{Comparison of TALIS and the Aura MLS}

As discussed in Sect. 2.2, TALIS has similar bands to the Aura MLS. The major difference between these two instruments is the spectrometers used in limb sounding. A simulation is performed to compare the performance of the main products between the TALIS FFT spectrometer and the Aura MLS "Standard" 25-channel spectrometer. Figures 9 to 11 show the retrieval products of TALIS and MLS; all the factors are identical, except the spectrometer.

According to the simulation results, TALIS can do a better job than the Aura MLS because of the wider bandwidth and finer resolution. The temperature precision of TALIS is $1.5 \mathrm{~K}$ better than the Aura MLS at about $15-30 \mathrm{~km}$ and the vertical resolution is also improved. The difference in precision becomes small above $50 \mathrm{~km} . \mathrm{H}_{2} \mathrm{O}$ precision is improved by about $2 \%-10 \%$ at about $15-50 \mathrm{~km} . \mathrm{O}_{3}$ precision is improved by about $3 \%-20 \%$ at about $10-60 \mathrm{~km}$. However, the digital autocorrelator spectrometers of the MLS which can improve the performance in the mesosphere are not considered here.

\subsection{Retrieval precision}

Since the simulation has been performed, an evaluation of the retrieval precision on the target species of TALIS is made. Results are plotted in Figs. 12 to 28. The precision (square root of diagonal elements of the error covariance matrix) is given for a single scan and averaged measurement, respectively, and the relative error is also provided. Auxiliary information about the averaging kernel function and measurement response are also included. Results are discussed in detail in the following.

\subsubsection{Better precision products}

Temperature, $\mathrm{H}_{2} \mathrm{O}, \mathrm{O}_{3}, \mathrm{HNO}_{3}, \mathrm{HCl}, \mathrm{N}_{2} \mathrm{O}$, and $\mathrm{ClO}$ are treated as better precision products because of the good precision for a single scan measurement. These products can be used in scientific research directly.

Atmospheric temperature is the most important parameter that can be retrieved with a high signal-to-noise ratio at lower frequency or a good vertical resolution at high frequency by using $\mathrm{O}_{2}$ lines. TALIS will use the $118 \mathrm{GHz}$ radiometer to detect the atmospheric temperature profile, with 

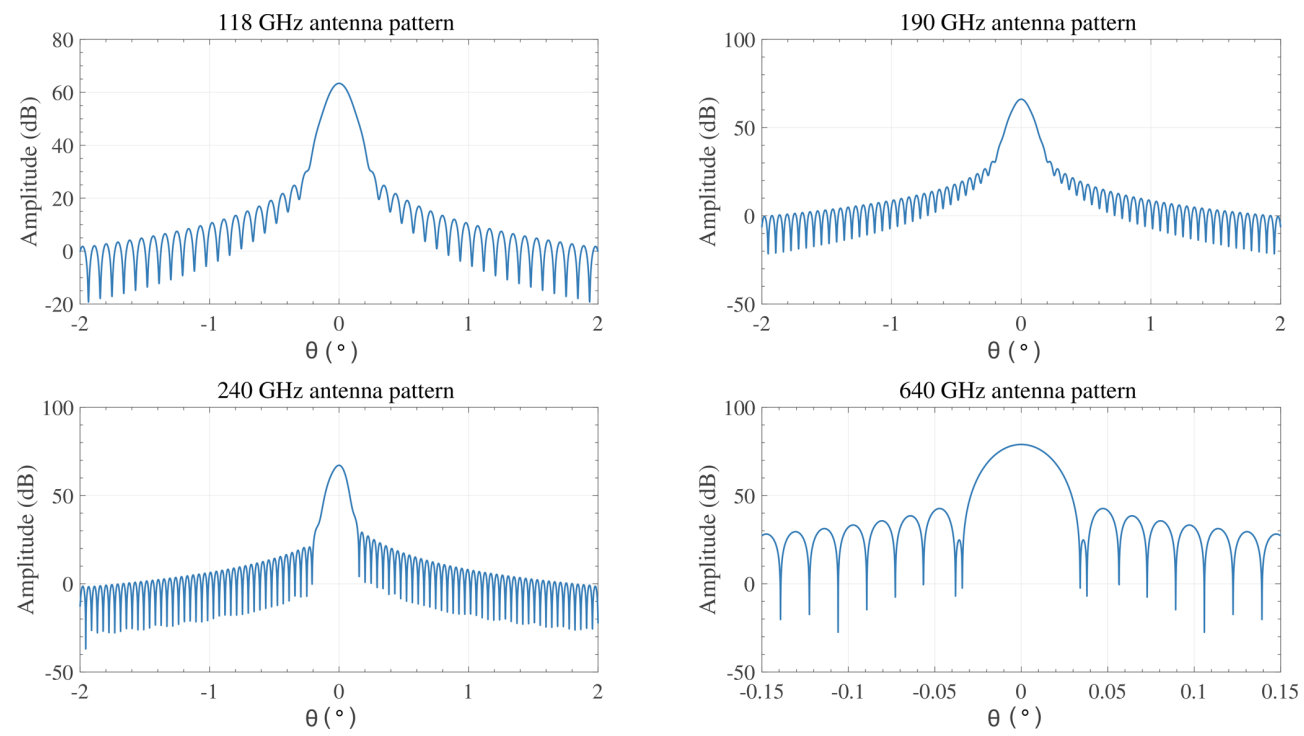

Figure 8. The antenna patterns of TALIS.
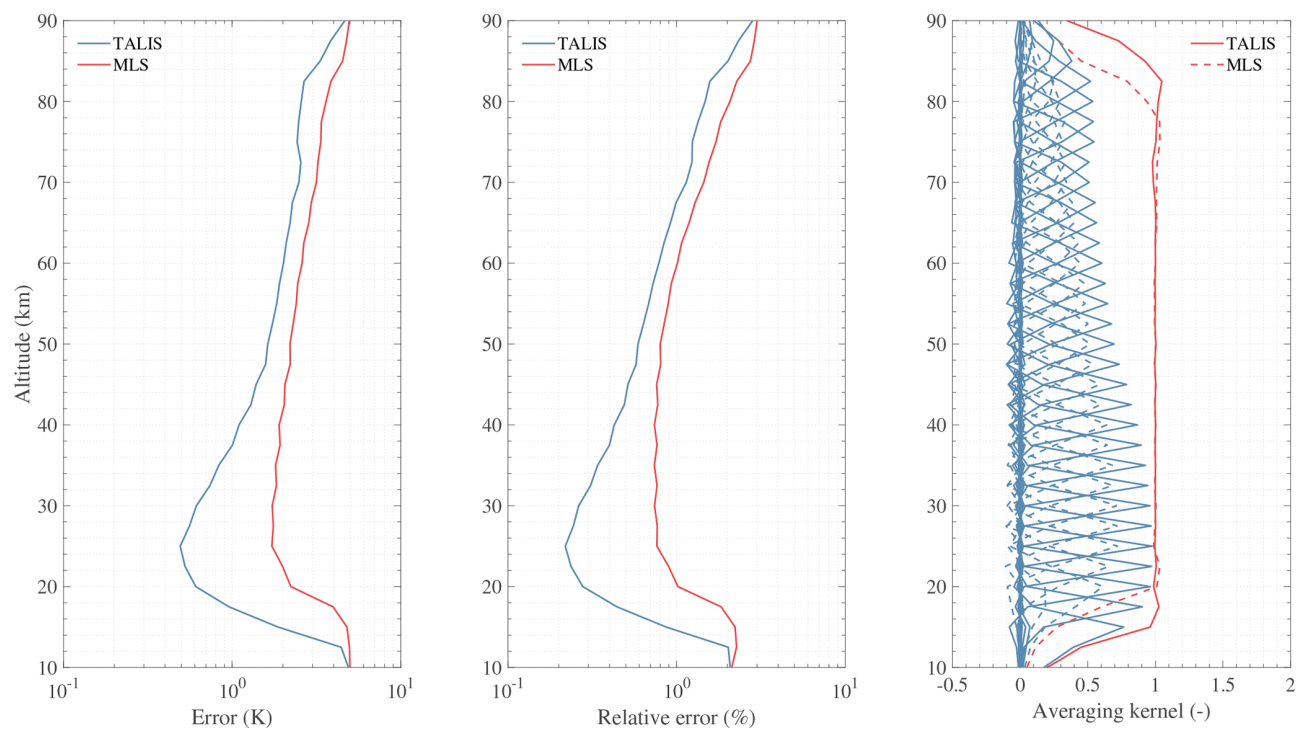

Figure 9. Temperature product comparison between the TALIS FFT spectrometer and the MLS "Standard" spectrometer using the 118.75 GHz line. All other factors are identical.

the 240 and $643 \mathrm{GHz}$ radiometers working as supplemental products. Results are shown in Fig. 12, and the sensitivity is significantly high at the $118 \mathrm{GHz}$ band. Single scan precision is good from 15 to $60 \mathrm{~km}$, with precision $<2 \mathrm{~K}$. The retrieval vertical resolution is $2.5-4 \mathrm{~km}$ below $50 \mathrm{~km}$ and $4-6 \mathrm{~km}$ from 50 to $80 \mathrm{~km}$. The precision of the averaged measurement will be $<1 \mathrm{~K}$ from 15 to $85 \mathrm{~km}$.

"Wide" filters of MLS make measurements extending down into the troposphere where TALIS lacks sensitivity. However, the $240 \mathrm{GHz}$ product can compensate for the loss of information since the precision is better in the upper troposphere (error $<1 \mathrm{~K}$ for a vertical resolution of $2.5-3 \mathrm{~km}$ between 10 and $15 \mathrm{~km}$ ). The result of the $643 \mathrm{GHz}$ band is similar to that of the $240 \mathrm{GHz}$ band.

Once the temperature profile is retrieved, the pressure profile can be calculated from the hydrostatic equilibrium equation using a known pressure and temperature at a reference tangent point. The pressure profile is not a direct product and is not shown here.

The $\mathrm{H}_{2} \mathrm{O}$ profile, another key parameter, can be measured by 190 and $643 \mathrm{GHz}$ radiometers. The $183.31 \mathrm{GHz}$ line is generally used by humidity sounders to detect water vapour with good precision. Figure 13 shows the retrieval precision will be $<10 \%$ from 10 to $55 \mathrm{~km}$ by $190 \mathrm{GHz}$ single 

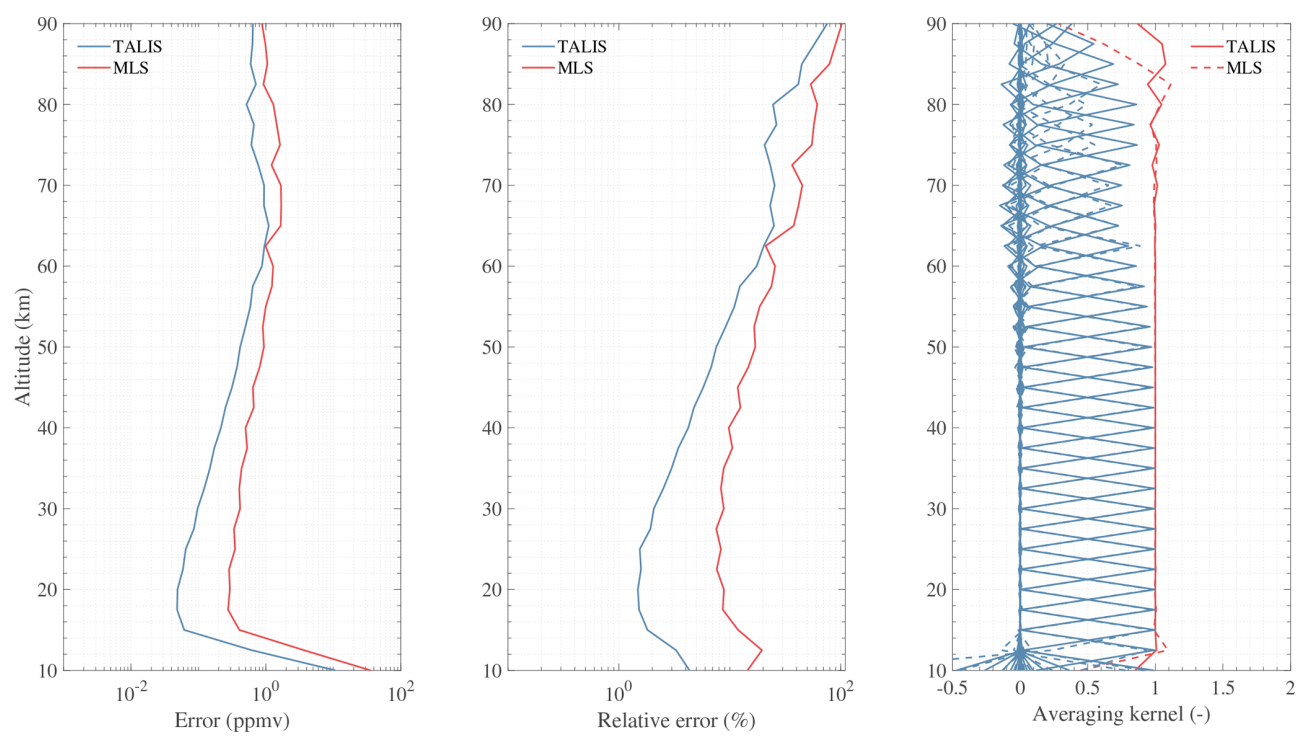

Figure 10. $\mathrm{H}_{2} \mathrm{O}$ product comparison between the TALIS FFT spectrometer and MLS "Standard" spectrometer using the $183.31 \mathrm{GHz}$ line. All other factors are identical.
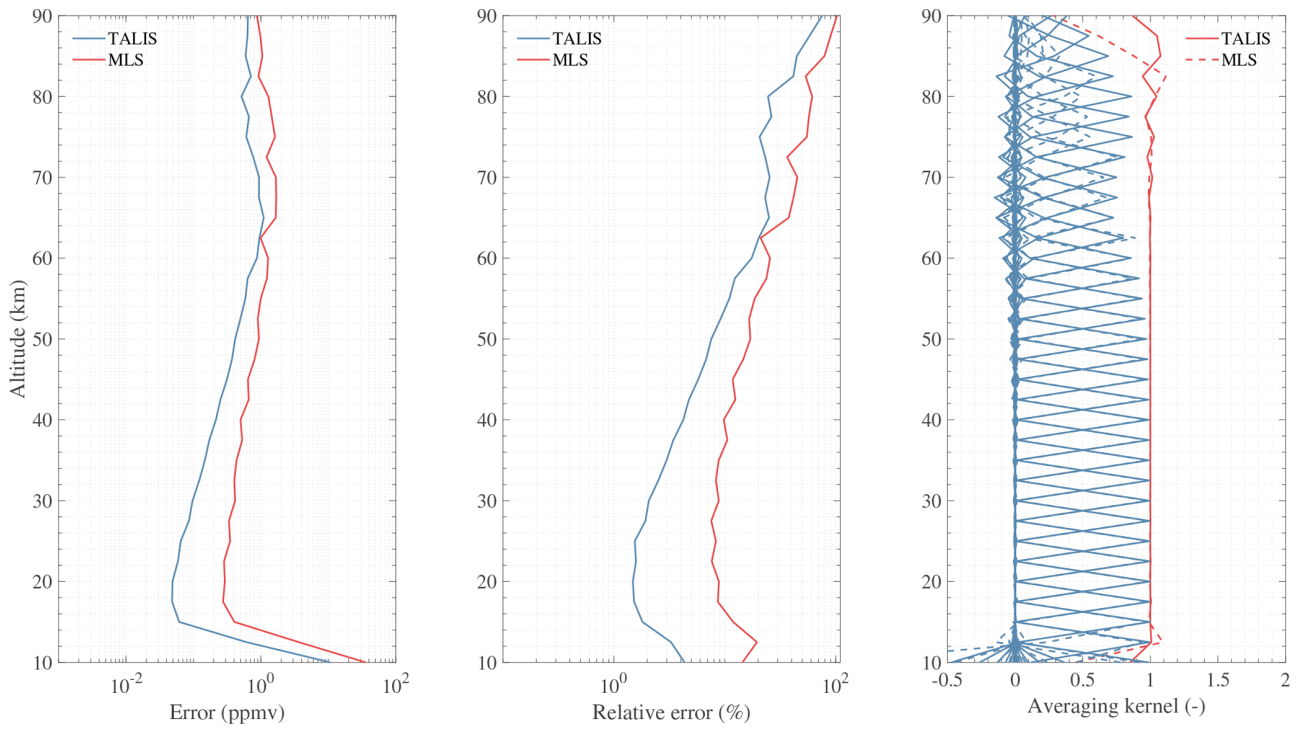

Figure 11. $\mathrm{O}_{3}$ product comparison between the TALIS FFT spectrometer and MLS "Standard" spectrometer using the 235.71 GHz line. All other factors are identical. 

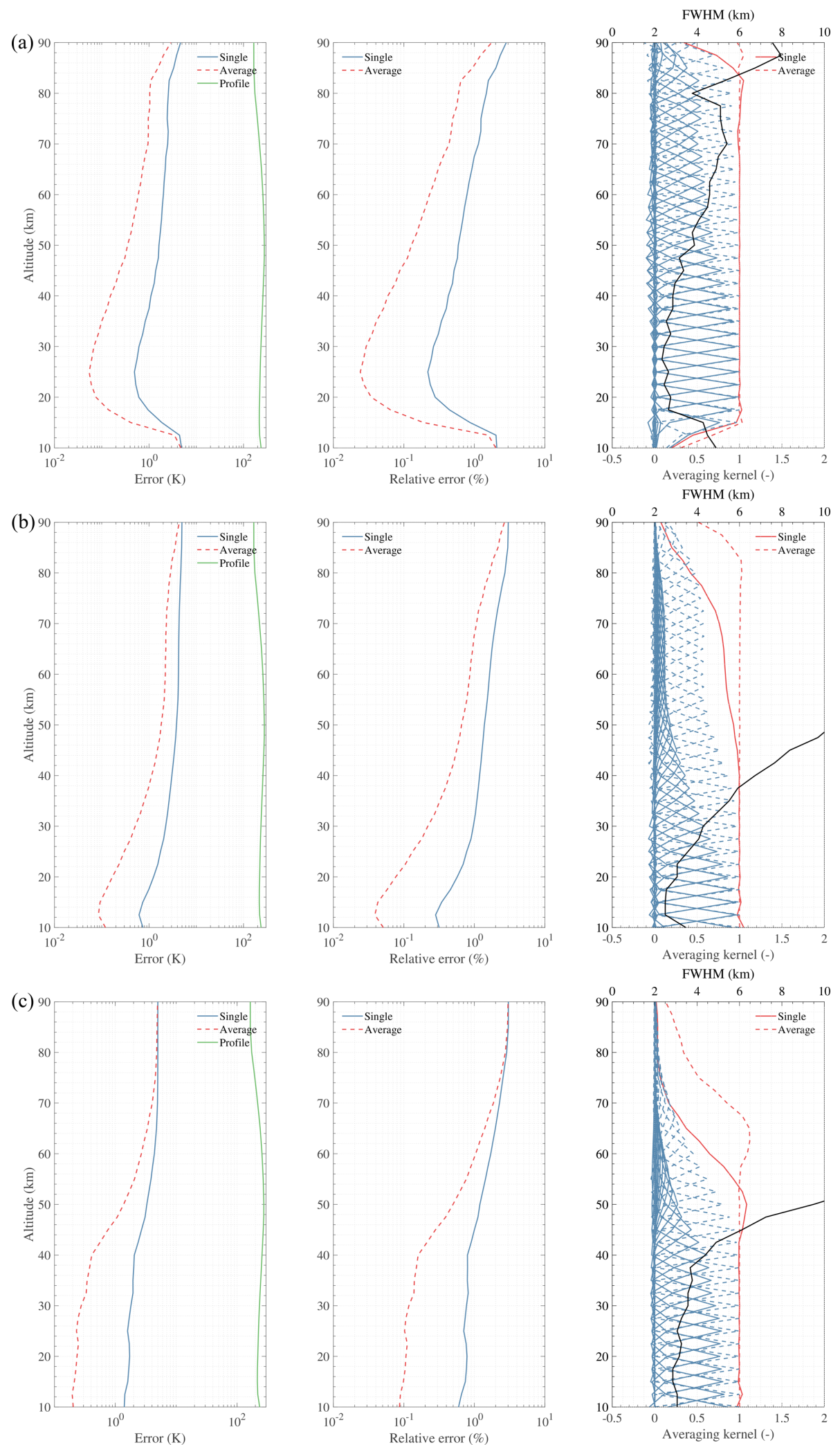

Figure 12. Simulation results of temperature retrieval using 118.75 (a), 233.95 (b), and $627.75 \mathrm{GHz}$ (c) lines. "Single" and "Average" represent the retrieval error using different noise. "Profile" represents the typical profile used in the simulation. The black solid line in the last panel represents the FWHM (i.e. vertical resolution). 

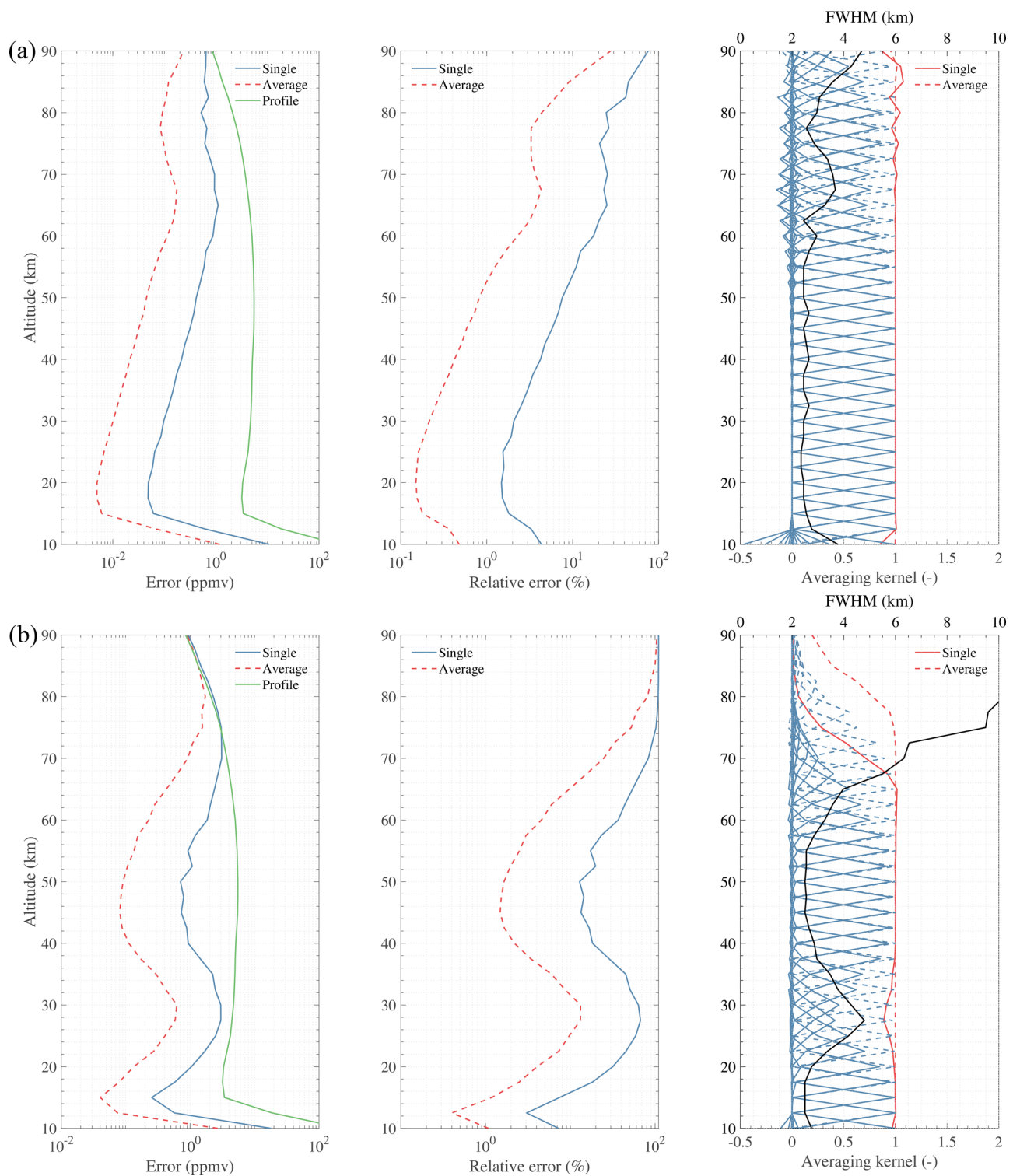

Figure 13. Simulation results of $\mathrm{H}_{2} \mathrm{O}$ retrieval using 183.31 (a) and $657.9 \mathrm{GHz}$ (b) lines. "Single" and "Average" represent the retrieval error using different noise. "Profile" represents the typical profile used in the simulation. The black solid line in the last panel represents the FWHM (i.e. vertical resolution).

scan measurement with a vertical resolution of $2.5-4 \mathrm{~km}$. Averaged measurement has retrieval precisions $<1 \%$ at 10 $55 \mathrm{~km}$ and $<5 \%$ at $10-80 \mathrm{~km}$. The profile can also be retrieved by the $643 \mathrm{GHz}$ radiometer with poorer precision.

$\mathrm{O}_{3}$ has quite strong intensity in most spectral regions of TALIS. All the radiometers except $118 \mathrm{GHz}$ can be used to observe this gas, which is important for energy balance (Fig. 14). The $240 \mathrm{GHz}$ radiometer which covers the $235.7 \mathrm{GHz}$ line has the highest $\mathrm{O}_{3}$ sensitivity. The profile can be retrieved with a single scan precision $<10 \%$ from 10 to $55 \mathrm{~km}$ and the vertical resolution is $2.5-3 \mathrm{~km}$. The vertical resolution will degrade to $3-6 \mathrm{~km}$ for altitudes higher than $70 \mathrm{~km}$. By averaging the measurements, the precision will be
$<5 \%$ at $10-70 \mathrm{~km}$. The other two bands show good performance from 15 to $55 \mathrm{~km}$ with a single scan precision $<10 \%$.

$\mathrm{HNO}_{3}$ is a common species in the stratosphere and has relatively strong lines at 240 and $643 \mathrm{GHz}$ bands. Figure 15 shows the results of $\mathrm{HNO}_{3}$ retrievals. The $240 \mathrm{GHz}$ radiometer can measure $\mathrm{HNO}_{3}$ at a $15-32 \mathrm{~km}$ altitude range with a single scan precision $<30 \%$ and the vertical resolution is $2.5-3 \mathrm{~km}$. Averaging the measurements can improve the retrieval with a precision $<10 \%$ from 15 to $35 \mathrm{~km}$. The $643 \mathrm{GHz}$ signal is stronger than that in the $240 \mathrm{GHz}$ band, but it is strongly absorbed by $\mathrm{O}_{3}$ below about $30 \mathrm{~km}$. However, after averaging the measurements, information can be 

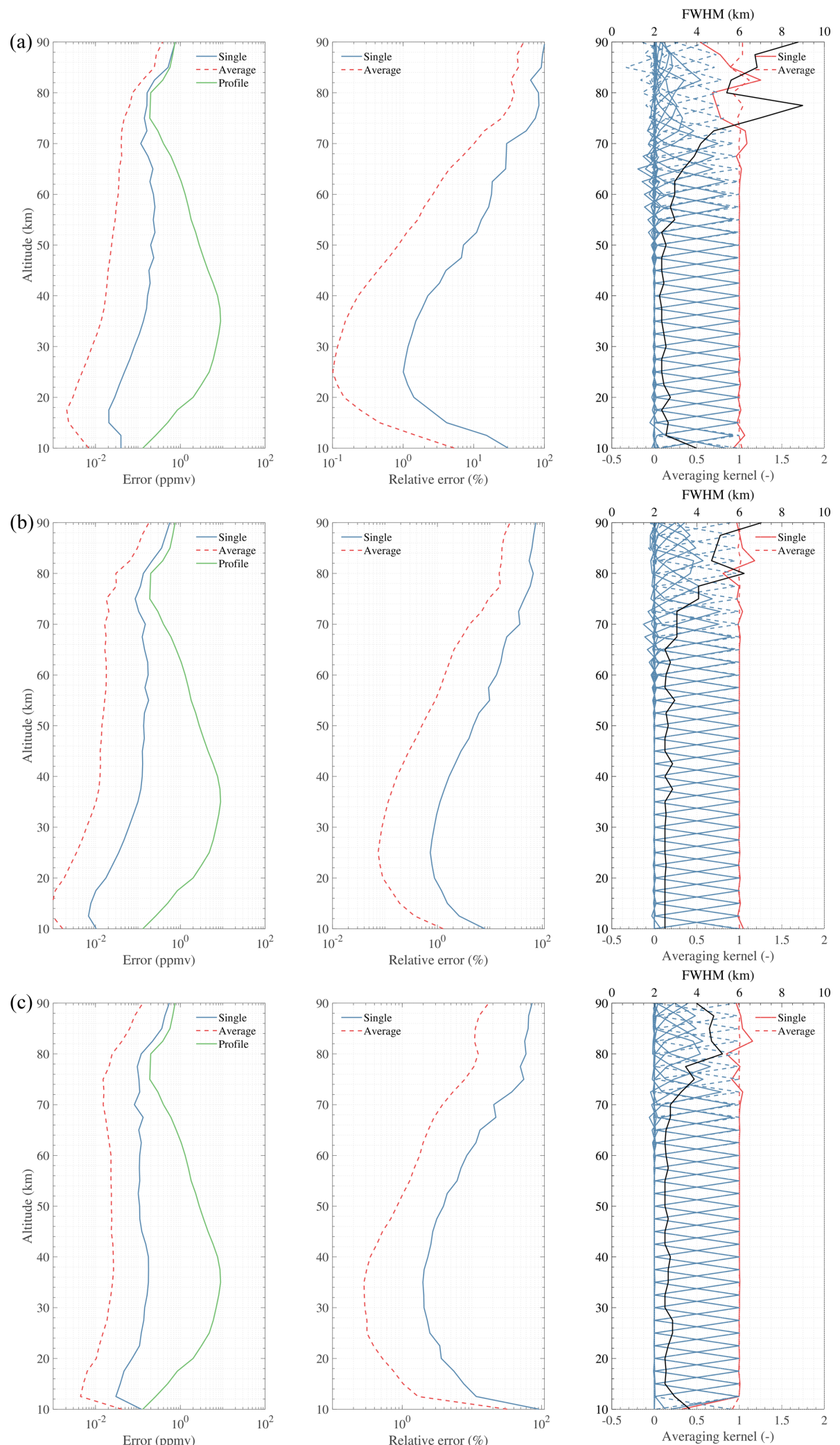

Figure 14. Simulation results of $\mathrm{O}_{3}$ retrieval using 190 (a), 235.7 (b), and $657.5 \mathrm{GHz}$ (c) lines. "Single" and "Average" represent the retrieval error using different noise. "Profile" represents the typical profile used in the simulation. The black solid line in the last panel represents the FWHM (i.e. vertical resolution). 

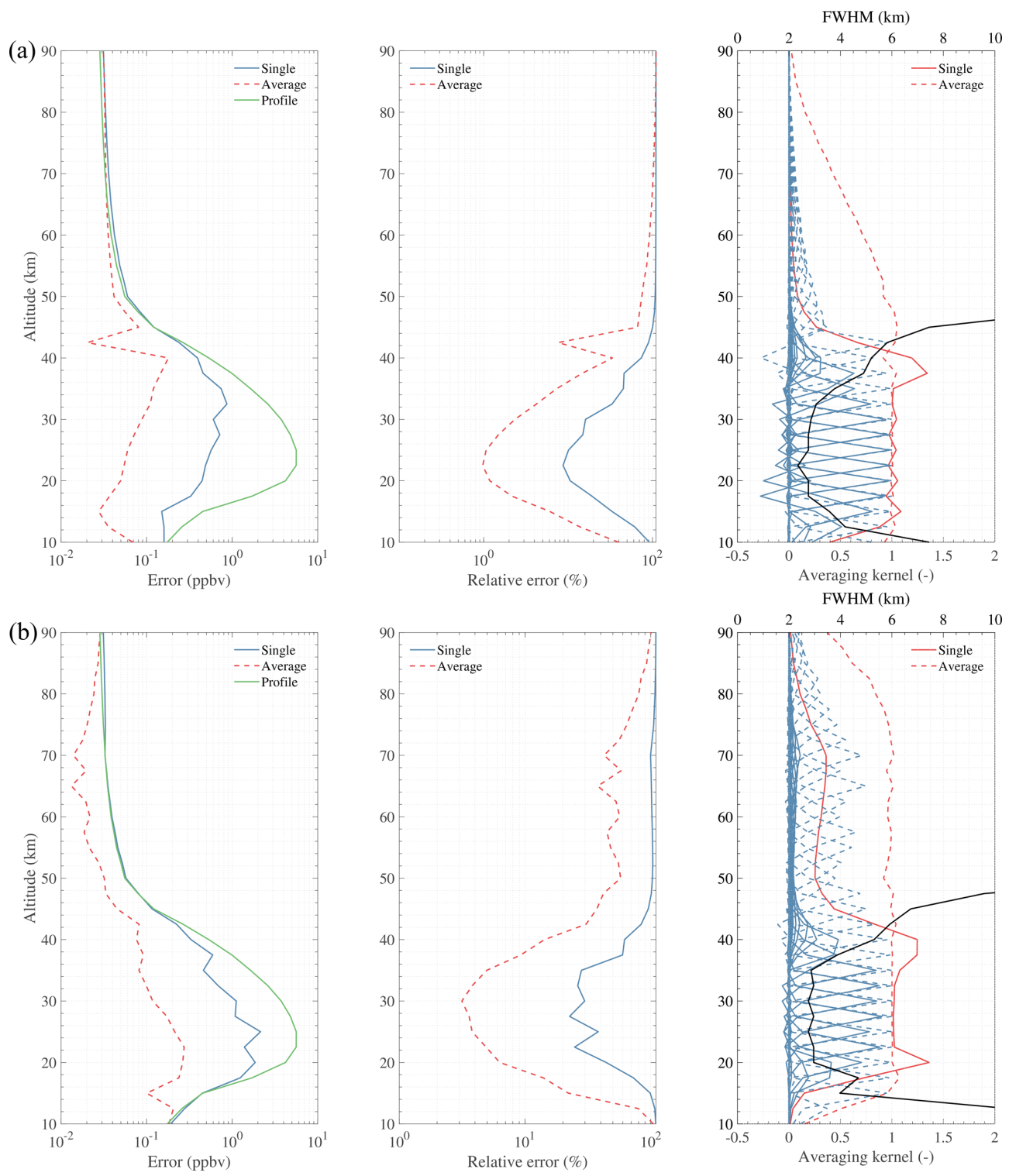

Figure 15. Simulation results of $\mathrm{HNO}_{3}$ retrieval using 244 (a) and $656 \mathrm{GHz}$ (b) lines. "Single" and "Average" represent the retrieval error using different noise. "Profile" represents the typical profile used in the simulation. The black solid line in the last panel represents the FWHM (i.e. vertical resolution).

retrieved between 15 and $70 \mathrm{~km}$ with a precision better than $60 \%$.

Figure 16 shows the expected precision of $\mathrm{HCl}$ observation. $\mathrm{HCl}$ can be measured at $15-50 \mathrm{~km}$ with $<20 \%$ single scan relative error with the vertical resolution of $2.5-3 \mathrm{~km}$. By averaging the measurements, the precision will be $<10 \%$ at $12-72 \mathrm{~km}$.

$\mathrm{N}_{2} \mathrm{O}$ can be retrieved from the band at $190 \mathrm{GHz}$ in the upper troposphere, while the band at $643 \mathrm{GHz}$ can provide more information and good precision in the stratosphere. Figure 17 shows that the single scan precision of $643 \mathrm{GHz}$ is $<20 \%$ at $12-32 \mathrm{~km}$ with the vertical resolution of $2.5 \mathrm{~km}$. By averaging the measurements, the precision will be $<10 \%$ from 10 to $42 \mathrm{~km}$. The $190 \mathrm{GHz}$ can give a similar precision at 10 $20 \mathrm{~km}$.

$\mathrm{ClO}$ can be retrieved from radiances measured by the 190 and $643 \mathrm{GHz}$ bands (Fig. 18). However, the result shows that the best retrievals are performed from the band at $643 \mathrm{GHz}$, but information can also be retrieved from the $190 \mathrm{GHz}$ radiometer with poorer precision. Single scan measurement from the $643 \mathrm{GHz}$ radiometer can be used to obtain $\mathrm{ClO}$ with $<40 \%$ precision from 30 to $45 \mathrm{~km}$, and the vertical resolution is about $2.5-4 \mathrm{~km}$ throughout the useful range. By averaging the measurements, precision will be $<30 \%$ from 23 to $57 \mathrm{~km}$. Since $\mathrm{ClO}$ vanishes in the middle stratosphere $(30-40 \mathrm{~km})$ during nighttime, the precision will be relatively 

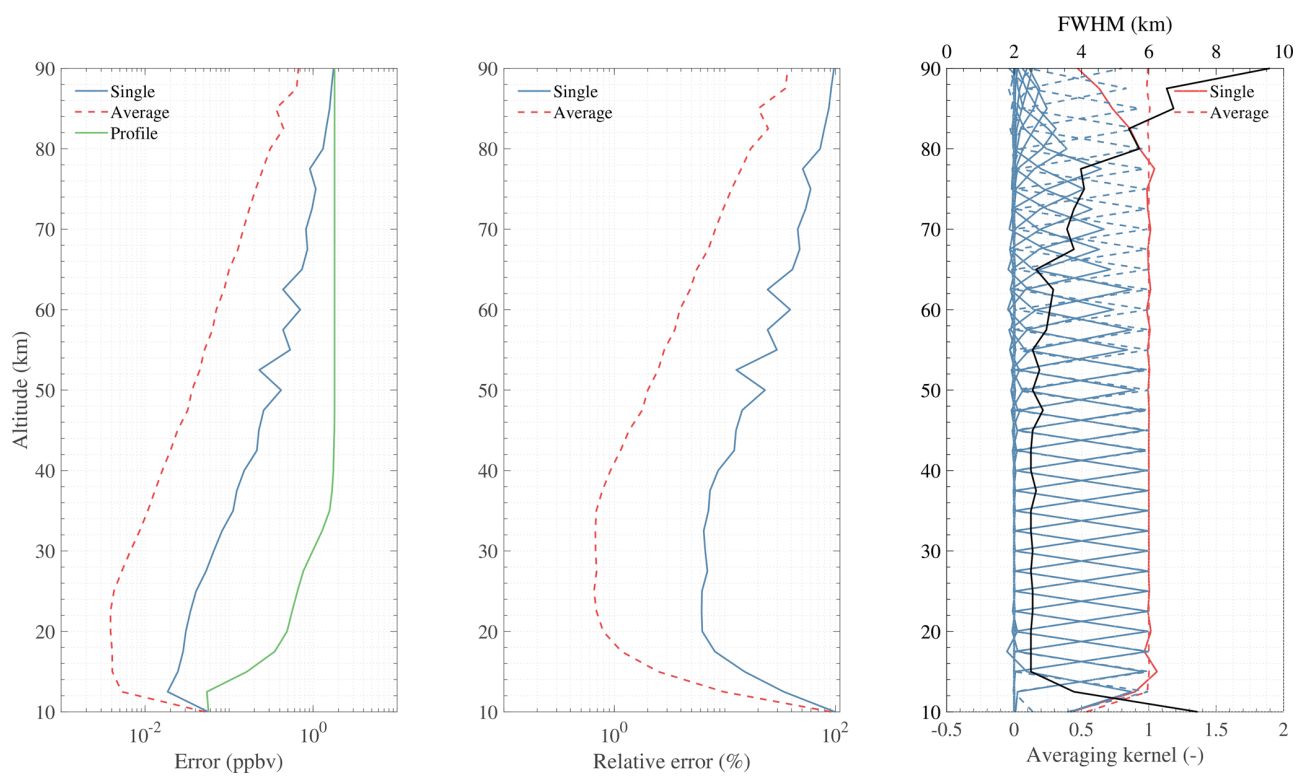

Figure 16. Simulation result of $\mathrm{HCl}$ retrieval using $624.9 \mathrm{GHz}$ lines. "Single" and "Average" represent the retrieval error using different noise. "Profile" represents the typical profile used in the simulation. The black solid line in the last panel represents the FWHM (i.e. vertical resolution).

worse in the nighttime. In the polar regions, the relative precision will be better between 20 and $25 \mathrm{~km}$ during chlorine activation.

\subsubsection{Medium precision products}

Medium precision products including $\mathrm{CO}, \mathrm{HCN}$, and $\mathrm{CH}_{3} \mathrm{Cl}$ mean that their single scan retrieval precisions are not satisfying but can be used to some degree. There is a choice for the user to select the single scan or averaged products.

$\mathrm{CO}$ can be measured using the 230.538 and $661.07 \mathrm{GHz}$ lines. Figure 19 shows that the $240 \mathrm{GHz}$ radiometer can provide CO information with $30 \%-90 \%$ single scan precision from 10 to $90 \mathrm{~km}$. The vertical resolution is in the range 3.5$5.5 \mathrm{~km}$ from the upper troposphere to the lower mesosphere, degrading to $6-10 \mathrm{~km}$ in the upper mesosphere. By using averaged measurements, $\mathrm{CO}$ can be retrieved with $<30 \%$ relative error at the range of $10-90 \mathrm{~km}$. However, the retrieval of the $643 \mathrm{GHz}$ measurement shows poorer precision.

$\mathrm{HCN}$ is measured by the $190 \mathrm{GHz}$ radiometer at the $177.26 \mathrm{GHz}$ line. The single scan precision is $<50 \%$ from 12 to $28 \mathrm{~km}$ and the vertical resolution is about $5 \mathrm{~km}$ at the height of $30 \mathrm{~km}$, degrading to $8 \mathrm{~km}$ at about $40 \mathrm{~km}$ (Fig. 20). By averaging the measurements, the relative error will be $<30 \%$ at $10-40 \mathrm{~km}$.

$\mathrm{CH}_{3} \mathrm{Cl}$ can be measured by the $643 \mathrm{GHz}$ radiometer. As the result shows (Fig. 21), the $649.5 \mathrm{GHz}$ band is suitable for $\mathrm{CH}_{3} \mathrm{Cl}$ observation in the upper troposphere and lower stratosphere. It can be measured with $<30 \%$ single scan precision from 12 to $23 \mathrm{~km}$, with $<20 \%$ averaged precision from 10 to $30 \mathrm{~km}$. The vertical resolution is about $3-4 \mathrm{~km}$ over most of the useful range.

\subsubsection{Poor precision products}

There are several weak lines in the spectral regions of TALIS, such as $\mathrm{HOCl}, \mathrm{BrO}$, and $\mathrm{HO}_{2}$. Significant averaging must be done to these measurements in order to obtain reliable and satisfying precision.

The $635.87 \mathrm{GHz}$ line is the most appropriate line for $\mathrm{HOCl}$ observation. However, the single scan retrieval has a poor precision of $60 \%-80 \%$ at $25-45 \mathrm{~km}$ with the vertical resolution of about $4-6 \mathrm{~km}$. Figure 22 reveals that $\mathrm{HOCl}$ can be retrieved from 20 to $50 \mathrm{~km}$ with an averaged measurement precision of $<50 \%$.

$\mathrm{BrO}$ can be measured by using the $624.768 \mathrm{GHz}$ spectral line. Figure 23 shows the simulation result of $\mathrm{BrO}$ retrieval. As the averaging kernel reveals, there is almost no useful information in single scan measurement because of the quite poor signal-to-noise ratio. Therefore, averaging is needed to obtain reliable and scientific results. The error is $50 \%$ from 24 to $48 \mathrm{~km}$ with the vertical resolution of about $4 \mathrm{~km}$.

$\mathrm{HO}_{2}$ can be measured by the $643 \mathrm{GHz}$ radiometer with < $50 \%$ precision at the vertical range of $30-90 \mathrm{~km}$ by using averaged data (Fig. 24). The precision of single scan retrieval is $55 \%-70 \%$ at $40-75 \mathrm{~km}$, which is not desirable because of the weak signal. The vertical resolution is about $6 \mathrm{~km}$. 
(a)
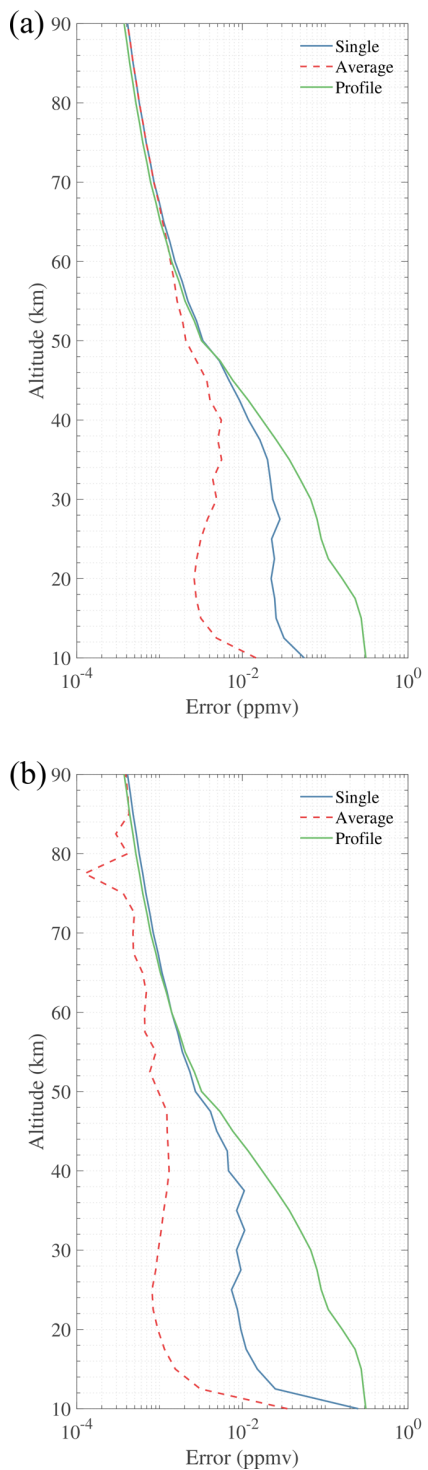
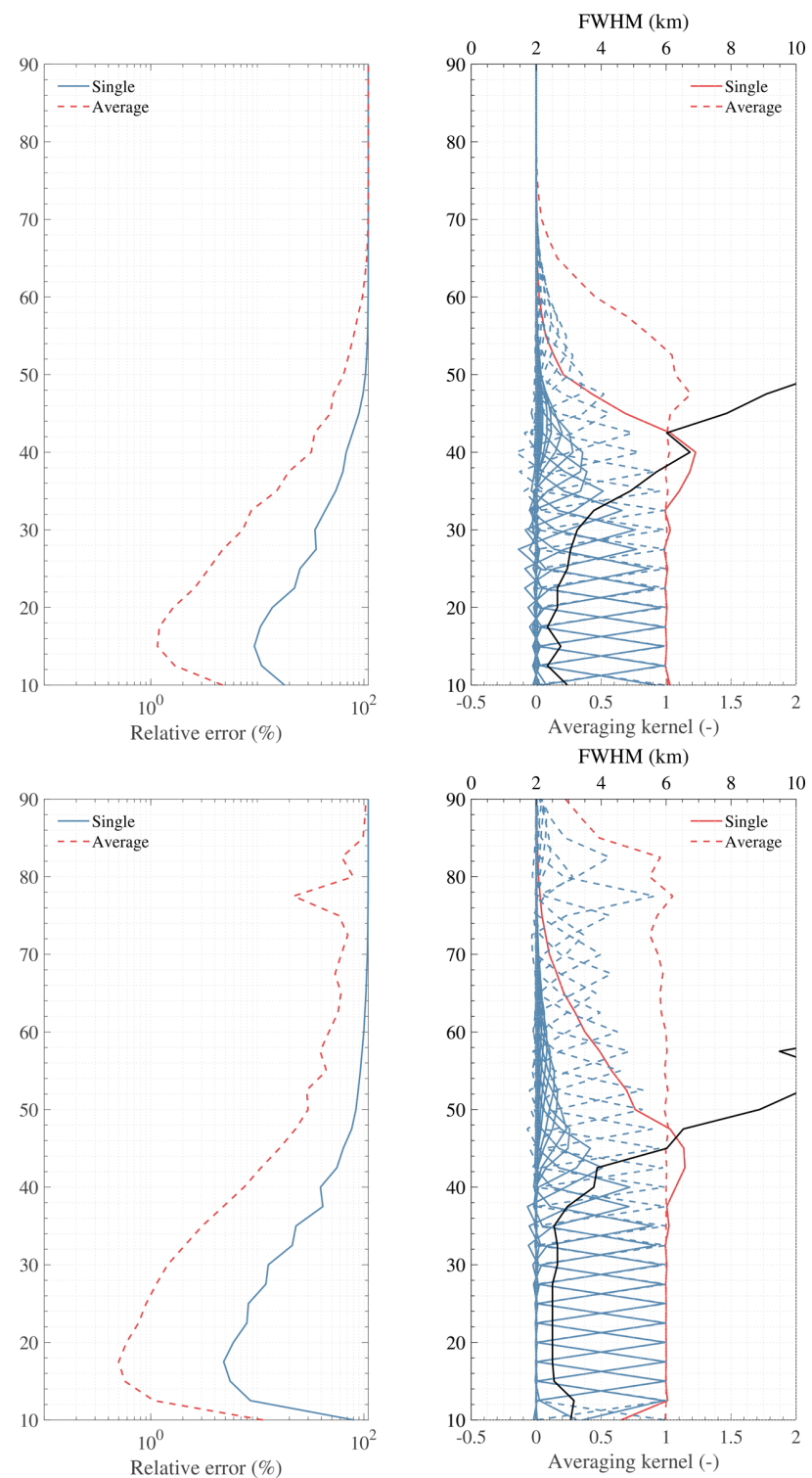

Figure 17. Simulation results of $\mathrm{N}_{2} \mathrm{O}$ retrieval using 200.98 (a) and $652.834 \mathrm{GHz}$ (b) lines. "Single" and "Average" represent the retrieval error using different noise. "Profile" represents the typical profile used in the simulation. The black solid line in the last panel represents the FWHM (i.e. vertical resolution).

\subsubsection{Promising products}

The unique products are the target species which are not covered by the Aura MLS but which are covered by TALIS. There are four gases: $\mathrm{NO}, \mathrm{NO}_{2}, \mathrm{H}_{2} \mathrm{CO}$, and $\mathrm{SO}_{2}$ (normal VMR). However, their signals all have weak intensity and must be averaged to improve the retrieval precision.

NO (daytime) can be retrieved from averaged data with $<50 \%$ precision at $28-90 \mathrm{~km}$ (Fig. 25), while it vanishes in the nighttime. The vertical resolution is about $4-10 \mathrm{~km}$, while its single scan measurement has little information in the area where NO largely exists.
$\mathrm{NO}_{2}$ (nighttime) has a weak line in the spectrum of the $240 \mathrm{GHz}$ band, and it vanishes in the daytime. Figure 26 shows that only averaged measurement can provide some information at $20-40 \mathrm{~km}$, with a precision of about $40 \%-60 \%$ in the nighttime. The vertical resolution is about $5 \mathrm{~km}$.

Although $\mathrm{H}_{2} \mathrm{CO}$ has a line at $656.45 \mathrm{GHz}$, its emission radiance is too weak. Almost no useful information can be obtained (Fig. 27). However, this line has the potential to measure $\mathrm{H}_{2} \mathrm{CO}$. More average or other effective methods should be applied to get acceptable precision.

The MLS standard $\mathrm{SO}_{2}$ product is taken from the $240 \mathrm{GHz}$ retrieval, but is only effective when its concentration is significantly enhanced. TALIS has both 240 and $643 \mathrm{GHz}$ ra- 
(a)
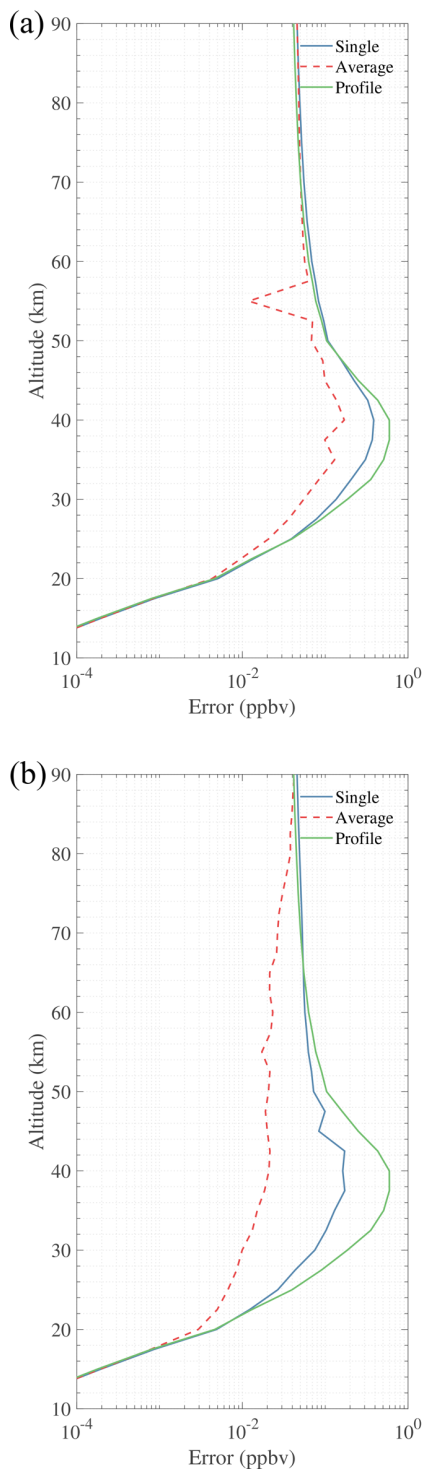
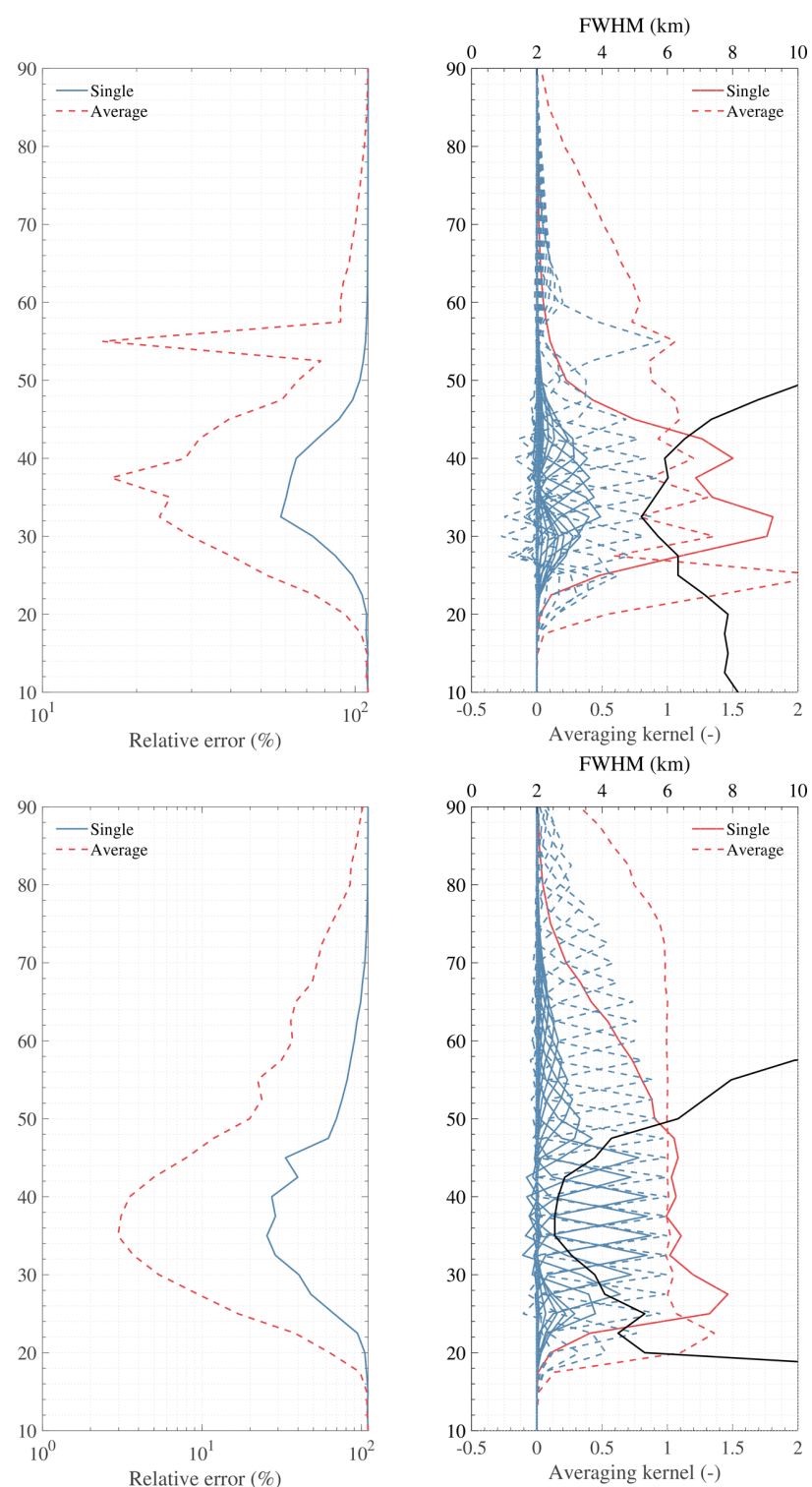

Figure 18. Simulation results of $\mathrm{ClO}$ retrieval using 203.4 (a) and $649.45 \mathrm{GHz}$ (b) lines. "Single" and "Average" represent the retrieval error using different noise. "Profile" represents the typical profile used in the simulation. The black solid line in the last panel represents the FWHM (i.e. vertical resolution).

diometers, which cover the lines of $\mathrm{SO}_{2}$. The $240 \mathrm{GHz}$ radiometer can be used to measure $\mathrm{SO}_{2}$ in the same way as MLS. The $643 \mathrm{GHz}$ radiometer can give the concentration of the nominal background. The averaged result shows that $\mathrm{SO}_{2}$ can be retrieved at $14-20 \mathrm{~km}, 46-70 \mathrm{~km}$ with the relative error about $<50 \%$ (Fig. 28). The vertical resolution is about $6 \mathrm{~km}$.

\section{Conclusions}

Simulation analysis for temperature and chemical species retrieval has been performed to assess the measurement per- formance of TALIS and to support the mission. This study mainly focuses on a large number of important chemical species in the middle and upper atmosphere which can be observed by the limb sounder. The results are summarised in Table 3.

Seven species show high sensitivity, sufficient for scientifically useful single profile retrievals; 118,240 , and $643 \mathrm{GHz}$ observations of $\mathrm{O}_{2}$ are used to estimate the temperature profile, which is quite important in meteorology. The $118 \mathrm{GHz}$ radiometer can obtain temperature with a precision $<2 \mathrm{~K}$ at $10-60 \mathrm{~km}$ and the 240 and $643 \mathrm{GHz}$ radiometers can provide more information in the upper troposphere (precision $<1 \mathrm{~K}$ at $10-15 \mathrm{~km}$ ). The $190 \mathrm{GHz}$ radiometer can be used 
(a)

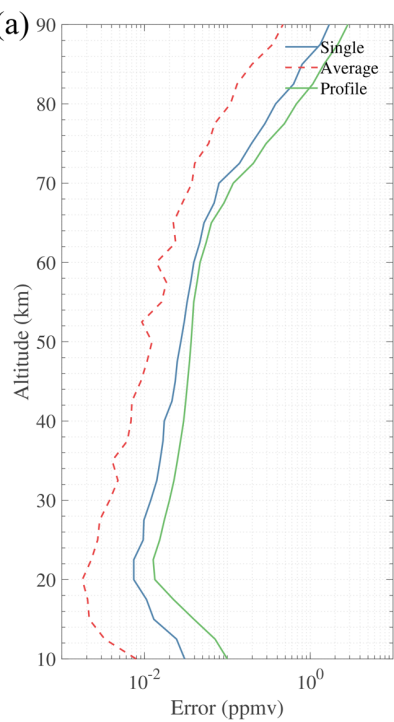

(b)

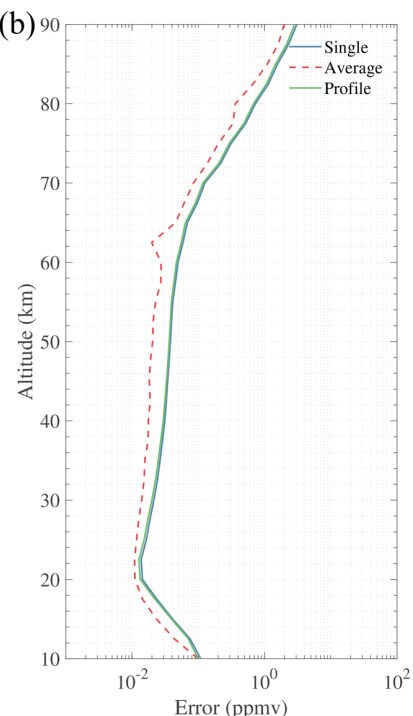

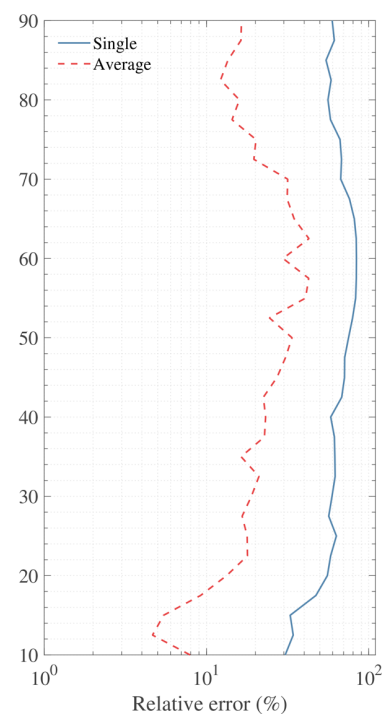
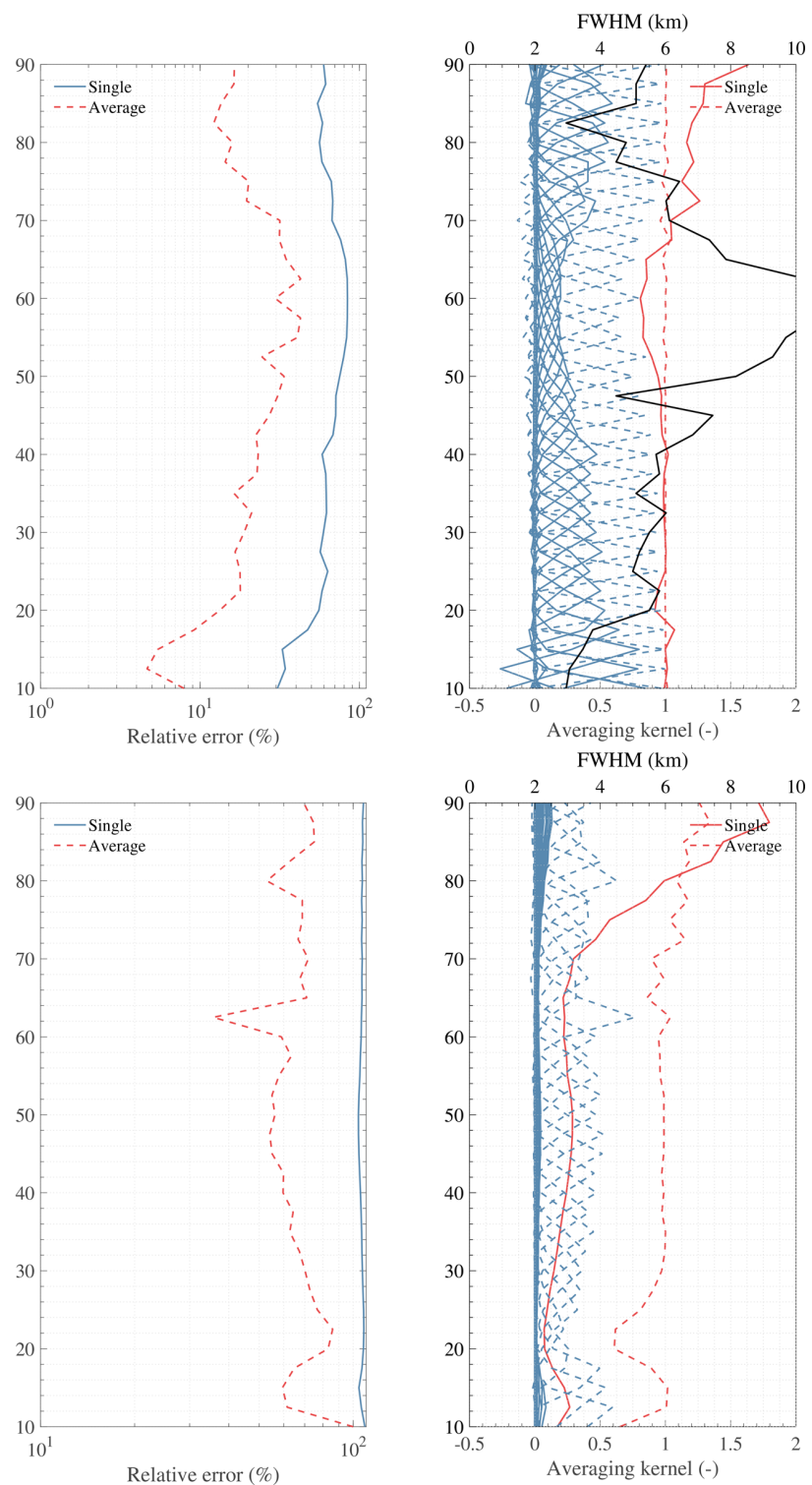

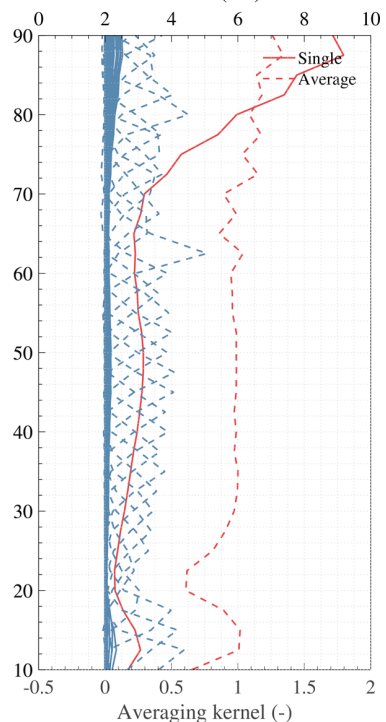

Figure 19. Simulation results of $\mathrm{CO}$ retrieval using 230.538 (a) and $661.07 \mathrm{GHz}$ (b) lines. "Single" and "Average" represent the retrieval error using different noise. "Profile" represents the typical profile used in the simulation. The black solid line in the last panel represents the FWHM (i.e. vertical resolution).

to measure $\mathrm{H}_{2} \mathrm{O}$ with a precision $<10 \%$ at $10-55 \mathrm{~km}$ and give information of upper tropospheric humidity. $\mathrm{O}_{3}$ can be measured by three radiometers, and the $240 \mathrm{GHz}$ radiometer has the best precision. The precision is $<10 \%$ from 10 to $55 \mathrm{~km}$ by single scan measurement. $\mathrm{HNO}_{3}$ can be derived from $240 \mathrm{GHz}$ retrieval with a precision $<30 \%$ at $15-32 \mathrm{~km}$. The precision of $\mathrm{HCl}$ single scan retrieval is $<20 \%$ over most of the useful range. The $643 \mathrm{GHz}$ radiometer can give a good estimate of the $\mathrm{N}_{2} \mathrm{O}$ profile, with a precision $<20 \%$ at $12-32 \mathrm{~km}$. The single scan precision of $\mathrm{ClO}$ measured by the $643 \mathrm{GHz}$ radiometer is about $<40 \%$ in the area where $\mathrm{ClO}$ mainly exists. $\mathrm{CH}_{3} \mathrm{Cl}$ can be measured in the upper troposphere and low stratosphere with a precision of about $30 \%$.
The profile of CO retrieved from $240 \mathrm{GHz}$ measurement is better than that from $643 \mathrm{GHz}$ measurement. The best sensitivity is found between 70 and $90 \mathrm{~km}$ where the VMR of $\mathrm{CO}$ is large, and the precision is about $50 \%$. $\mathrm{HCN}$ has $50 \%$ single scan precision at $12-28 \mathrm{~km}$, which may need to be averaged. Other measurements, such as $\mathrm{HO}_{2}, \mathrm{HOCl}, \mathrm{NO}, \mathrm{NO}_{2}$, $\mathrm{BrO}, \mathrm{SO}_{2}$, and $\mathrm{H}_{2} \mathrm{CO}$, must be significantly averaged before scientific use because of the weak signals.

Apart from these products, some potential products will be discussed in the future works. Line-of-sight wind is important information which could be measured by TALIS. Cloud ice water content (IWC) is also an essential product provided by the passive microwave radiometer. Future studies will also 

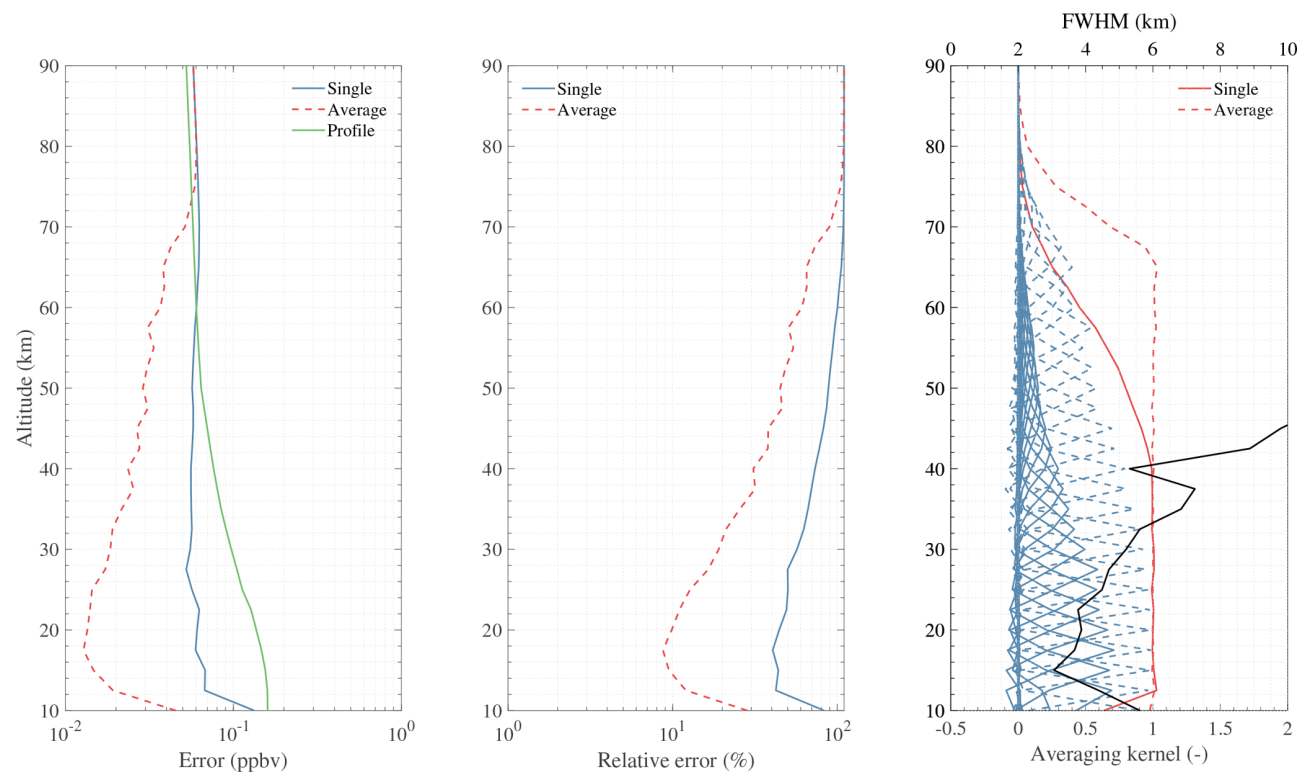

Figure 20. Simulation result of HCN retrieval using 177.26 GHz lines. "Single" and "Average" represent the retrieval error using different noise. "Profile" represents the typical profile used in the simulation. The black solid line in the last panel represents the FWHM (i.e. vertical resolution).
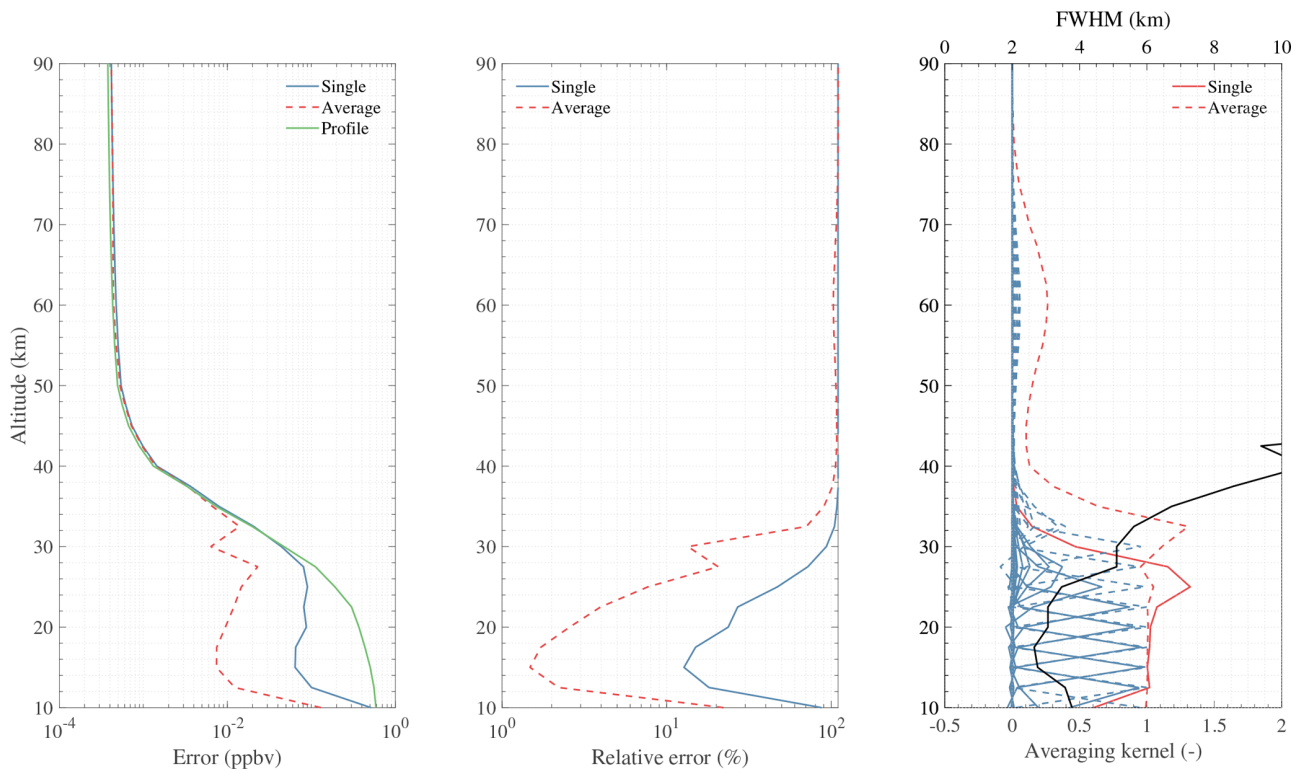

Figure 21. Simulation results of $\mathrm{CH}_{3} \mathrm{Cl}$ retrieval using $649.5 \mathrm{GHz}$ lines. "Single" and "Average" represent the retrieval error using different noise. "Profile" represents the typical profile used in the simulation. The black solid line in the last panel represents the FWHM (i.e. vertical resolution). 

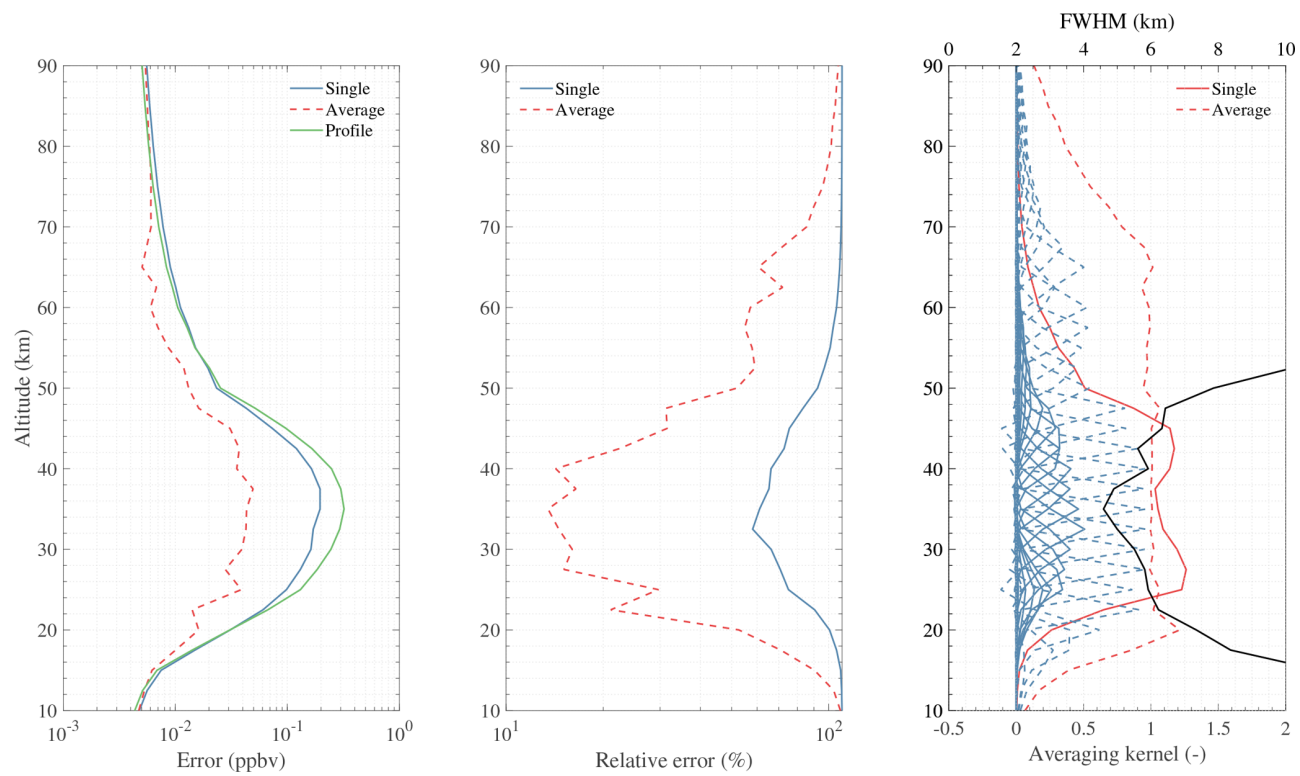

Figure 22. Simulation result of $\mathrm{HOCl}$ retrieval using $635.87 \mathrm{GHz}$ lines. "Single" and "Average" represent the retrieval error using different noise. "Profile" represents the typical profile used in the simulation. The black solid line in the last panel represents the FWHM (i.e. vertical resolution).
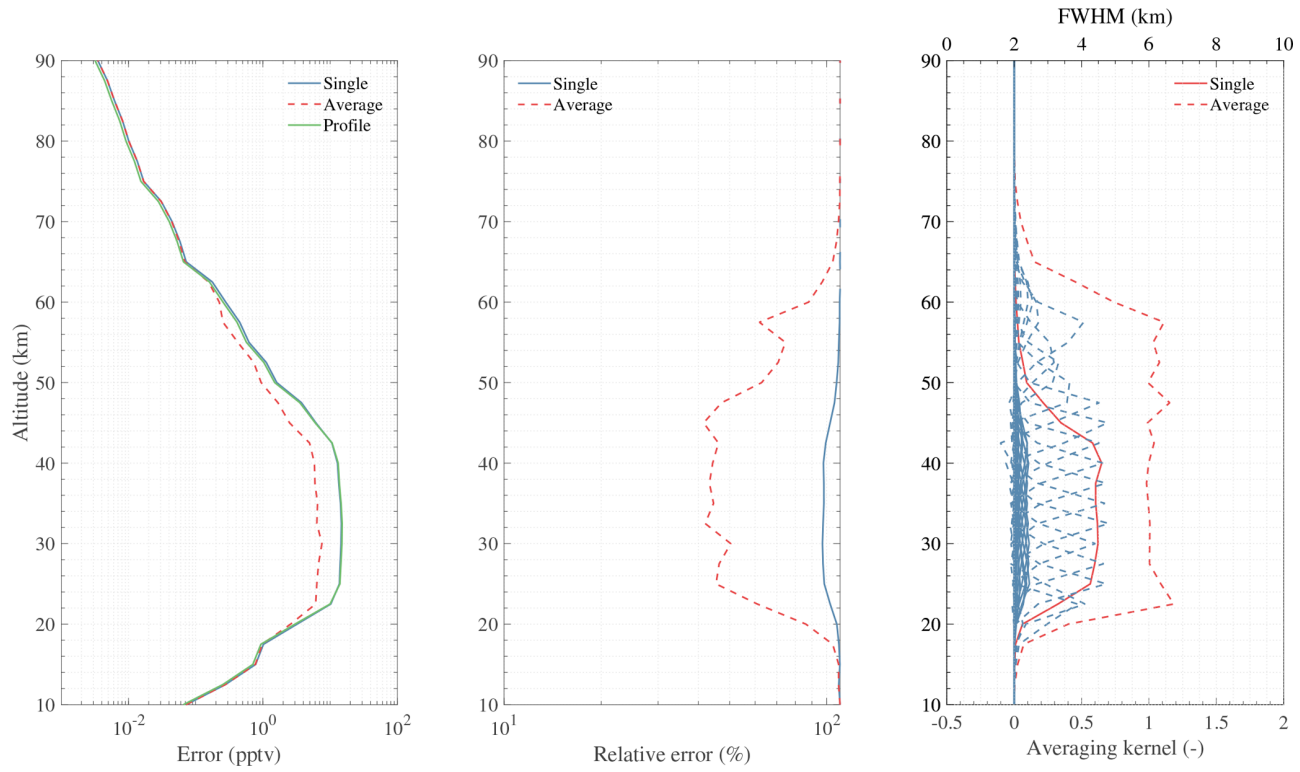

Figure 23. Simulation results of BrO retrieval using $624.768 \mathrm{GHz}$ lines. "Single" and "Average" represent the retrieval error using different noise. "Profile" represents the typical profile used in the simulation. The black solid line in the last panel represents the FWHM (i.e. vertical resolution). 

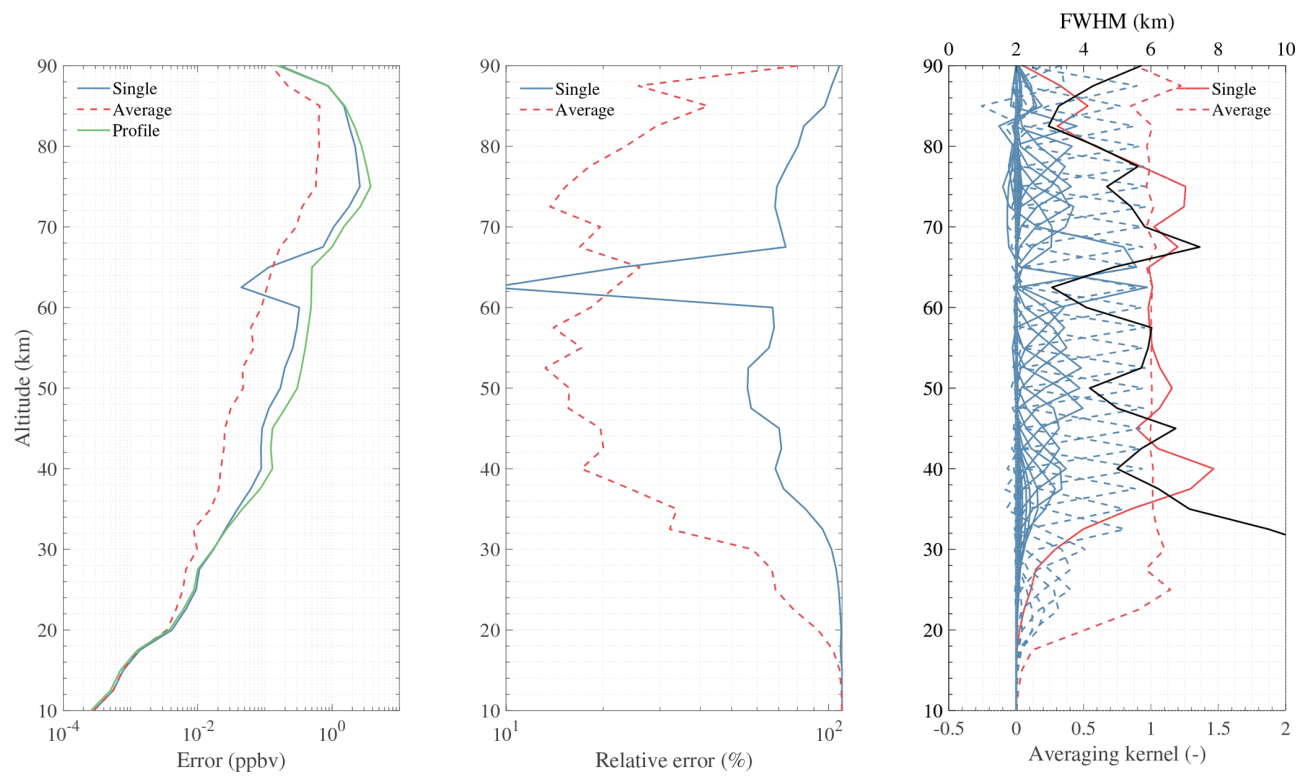

Figure 24. Simulation results of $\mathrm{HO}_{2}$ retrieval using $649.701 \mathrm{GHz}$ lines. "Single" and "Average" represent the retrieval error using different noise. "Profile" represents the typical profile used in the simulation. The black solid line in the last panel represents the FWHM (i.e. vertical resolution).
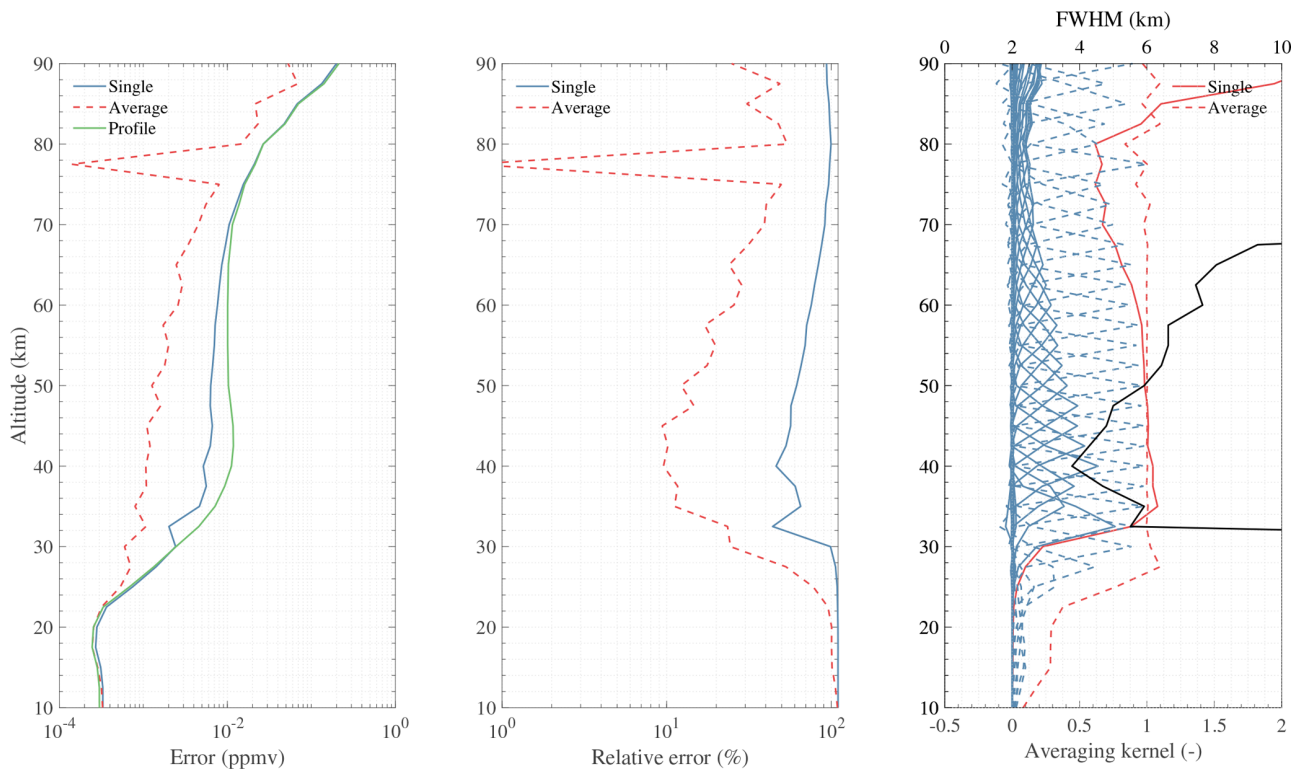

Figure 25. Simulation result of NO retrieval using $651.75 \mathrm{GHz}$ lines. "Single" and "Average" represent the retrieval error using different noise. "Profile" represents the typical profile used in the simulation. The black solid line in the last panel represents the FWHM (i.e. vertical resolution). 

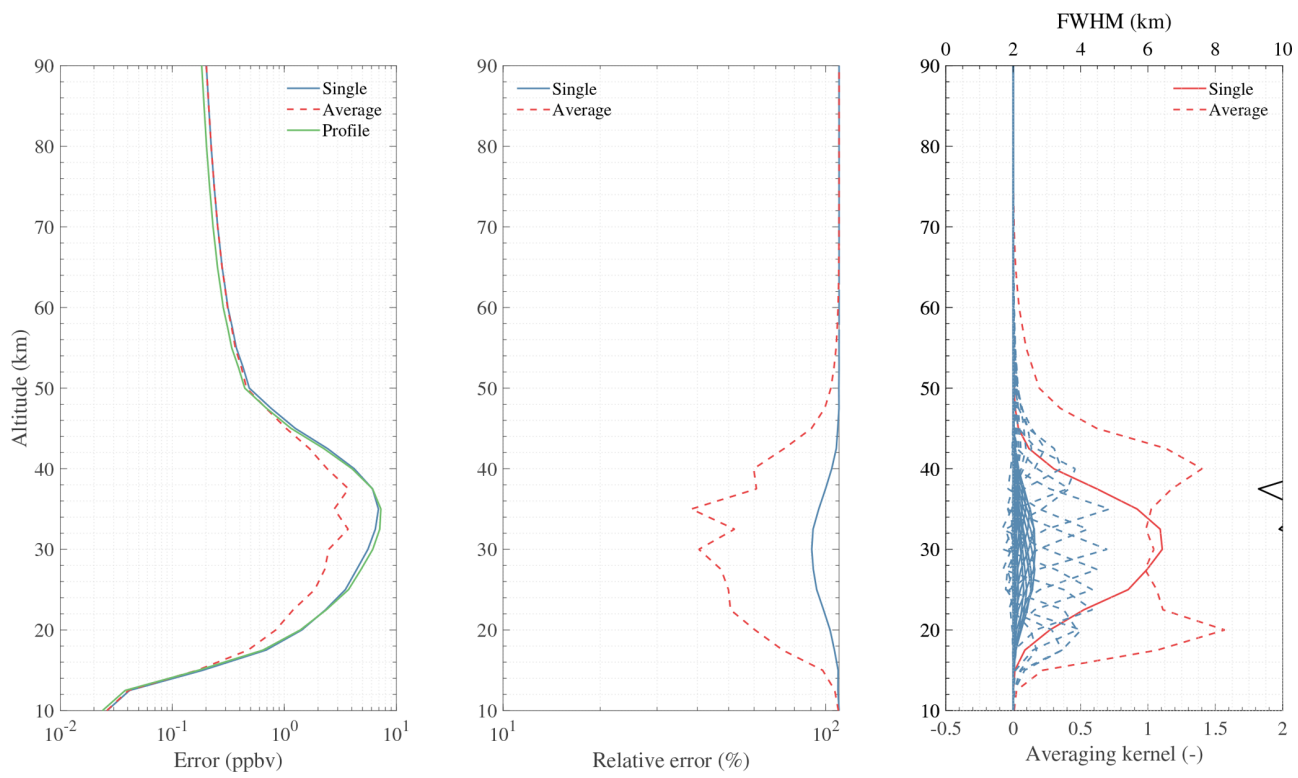

Figure 26. Simulation result of $\mathrm{NO}_{2}$ retrieval using $232.7 \mathrm{GHz}$ lines. "Single" and "Average" represent the retrieval error using different noise. "Profile" represents the typical profile used in the simulation. The black solid line in the last panel represents the FWHM (i.e. vertical resolution).
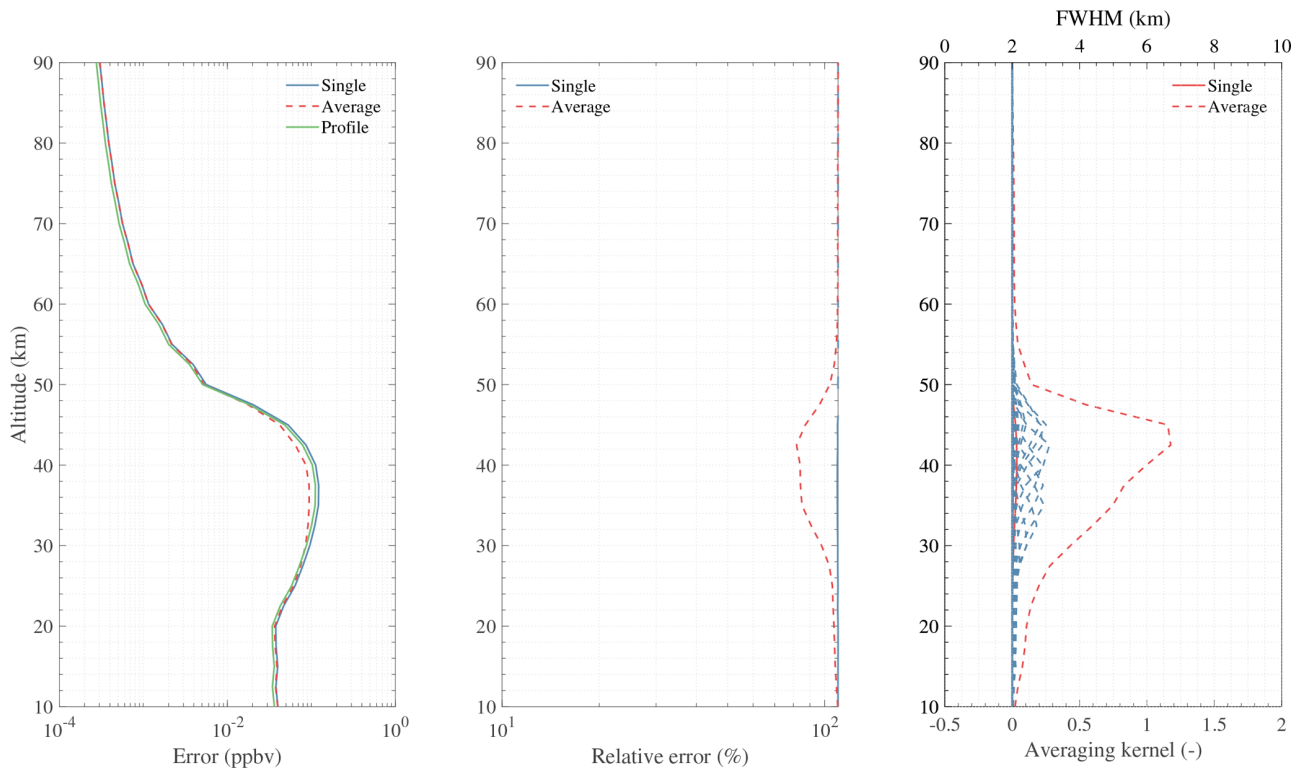

Figure 27. Simulation result of $\mathrm{H}_{2} \mathrm{CO}$ retrieval using $656.45 \mathrm{GHz}$ lines. "Single" and "Average" represent the retrieval error using different noise. "Profile" represents the typical profile used in the simulation. The black solid line in the last panel represents the FWHM (i.e. vertical resolution) 

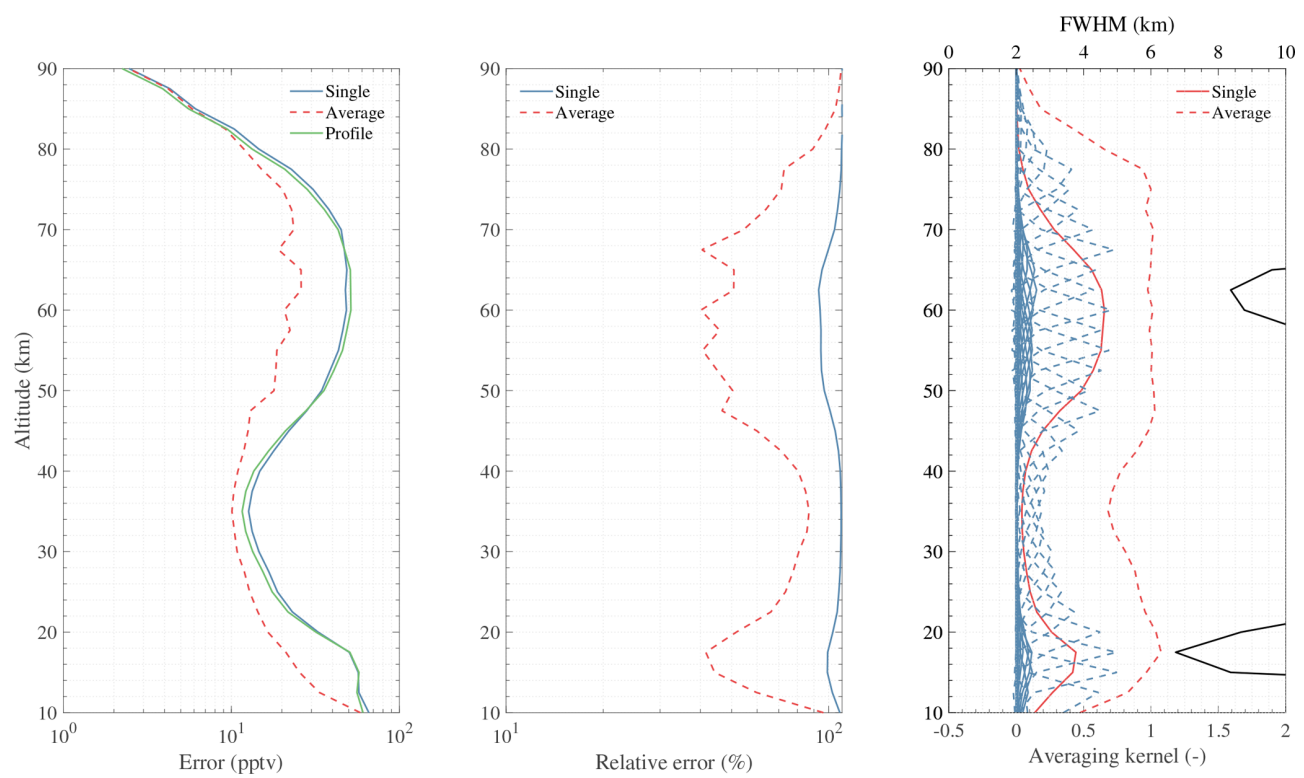

Figure 28. Simulation result of $\mathrm{SO}_{2}$ retrieval using $659 \mathrm{GHz}$ lines. "Single" and "Average" represent the retrieval error using different noise. "Profile" represents the typical profile used in the simulation. The black solid line in the last panel represents the FWHM (i.e. vertical resolution).

Table 3. Simulation results of TALIS retrieval precision.

\begin{tabular}{|c|c|c|c|}
\hline Product & Radiometer & Single precision & Average precision \\
\hline Temperature & $118 \mathrm{GHz}, 240 \mathrm{GHz}$ & $<2 \mathrm{~K}(10-60 \mathrm{~km})$ & $<2 \mathrm{~K}(10-85 \mathrm{~km})$ \\
\hline $\mathrm{H}_{2} \mathrm{O}$ & $190 \mathrm{GHz}$ & $<10 \%(10-55 \mathrm{~km})$ & $<5 \%(10-80 \mathrm{~km})$ \\
\hline $\mathrm{O}_{3}$ & $240 \mathrm{GHz}$ & $<10 \%(10-55 \mathrm{~km})$ & $<5 \%(10-70 \mathrm{~km})$ \\
\hline $\mathrm{HCl}$ & $643 \mathrm{GHz}$ & $<20 \%(15-50 \mathrm{~km})$ & $<10 \%(12-72 \mathrm{~km})$ \\
\hline $\mathrm{N}_{2} \mathrm{O}$ & $643 \mathrm{GHz}$ & $<20 \%(12-32 \mathrm{~km})$ & $<10 \%(10-42 \mathrm{~km})$ \\
\hline $\mathrm{HNO}_{3}$ & $240 \mathrm{GHz}$ & $<30 \%(15-32 \mathrm{~km})$ & $<10 \%(15-35 \mathrm{~km})$ \\
\hline $\mathrm{ClO}$ & $643 \mathrm{GHz}$ & $<40 \%(30-45 \mathrm{~km})$ & $<30 \%(23-57 \mathrm{~km})$ \\
\hline $\mathrm{CO}$ & $240 \mathrm{GHz}$ & $30 \%-90 \%(10-90 \mathrm{~km})$ & $<30 \%(10-90 \mathrm{~km})$ \\
\hline $\mathrm{HCN}$ & $190 \mathrm{GHz}$ & $<50 \%(12-28 \mathrm{~km})$ & $<30 \%(10-40 \mathrm{~km})$ \\
\hline $\mathrm{CH}_{3} \mathrm{Cl}$ & $643 \mathrm{GHz}$ & $<30 \%(12-23 \mathrm{~km})$ & $<20 \%(10-30 \mathrm{~km})$ \\
\hline $\mathrm{HOCl}$ & $643 \mathrm{GHz}$ & $60 \%-80 \%(25-45 \mathrm{~km})$ & $<50 \%(20-50 \mathrm{~km})$ \\
\hline $\mathrm{BrO}$ & $643 \mathrm{GHz}$ & / & $<50 \%(24-48 \mathrm{~km})$ \\
\hline $\mathrm{HO}_{2}$ & $643 \mathrm{GHz}$ & $<70 \%(40-75 \mathrm{~km})$ & $<50 \%(30-90 \mathrm{~km})$ \\
\hline $\mathrm{NO}$ & $643 \mathrm{GHz}$ & $50 \%-70 \%(33-55 \mathrm{~km})$ & $<50 \%(28-90 \mathrm{~km})$ \\
\hline $\mathrm{NO}_{2}$ & $240 \mathrm{GHz}$ & I & $40 \%-60 \%(20-40 \mathrm{~km})$ \\
\hline $\mathrm{H}_{2} \mathrm{CO}$ & $643 \mathrm{GHz}$ & I & / \\
\hline $\mathrm{SO}_{2}$ & $643 \mathrm{GHz}$ & I & $<50 \%(14-20,46-70 \mathrm{~km})$ \\
\hline
\end{tabular}

investigate the Zeeman effect since it polarises and changes the shape of the $\mathrm{O}_{2}$ lines.

TALIS has the potential to monitor chemical composition in the whole of Earth's atmosphere, which is important for numerical weather prediction models and to characterise the long-time change in climate. Measurement data can be used for atmospheric chemistry and dynamics study, which is quite important for geoscience. This paper is the preliminary analysis of the instrument. More studies such as calibration research and error analysis will be performed in the future.
Code and data availability. ARTS can be downloaded at http:// www.radiativetransfer.org/getarts/ (last access: 15 December 2017; University of Hamburg and Chalmers University of Technology, 2017b). Qpack is included in the Atmlab which can be downloaded from http://www.radiativetransfer.org/tools/ (last access: 15 December 2017; University of Hamburg and Chalmers University of Technology, 2017a). Profiles and spectroscopy data of Perrin and HITRAN are included in ARTS XML Data. The JPL molecular spectroscopy catalogue is available at https://spec.jpl.nasa.gov/ (last access: 21 February 2019; NASA JPL, 2019). MLS version 4.2 data 
can be obtained at https://doi.org/10.5067/Aura/MLS/DATA3020 (Millan et al., 2016).

Author contributions. ZW designed the mission concept. WW performed the simulation and wrote the manuscript. WW and YD analysed the results. ZW edited the article.

Competing interests. The authors declare that they have no conflict of interest.

Acknowledgements. The authors would like to thank the ARTS and Qpack development teams for assistance in configuring and running the model. The authors thank the JPL for providing spectroscopy data and MLS data. They would also like to thank the reviewers and the editors for their valuable and helpful suggestions.

Review statement. This paper was edited by Bernd Funke and reviewed by Hugh C. Pumphrey and two anonymous referees.

\section{References}

Barath, F. T., Chavez, M. C., Cofield, R. E., Flower, D. A., Frerking, M. A., Gram, M. B., Harris, W. M., Holden, J. R., Jarnot, R. F., Kloezeman, W. G., Klose, G. J., Lau, G. K., Loo, M. S., Maddison, B. J., Mattauch, R. J., McKinney, R. P., Peckham, G. E., Pickett, H. M., Pickett, G., Soltis, F. S., Suttie, R. A., Tarsala, J. A., Waters, J. W., and Wilson, W. J.: The Upper Atmosphere Research Satellite microwave limb sounder instrument, J. Geophys. Res., 98, 10751-10762, https://doi.org/10.1029/93JD00798, 1993.

Baron, P., Ricaud, P., de la Nöe, J., Eriksson, P., Merino, F., Ridal, M., and Murtagh, D. P.: Studies for the Odin Sub-Millimetre Radiometer. II. Retrieval methodology, Can. J. Phys., 80, 341-356, https://doi.org/10.1139/P01-150, 2002.

Baron, P., Urban, J., Sagawa, H., Möller, J., Murtagh, D. P., Mendrok, J., Dupuy, E., Sato, T. O., Ochiai, S., Suzuki, K., Manabe, T., Nishibori, T., Kikuchi, K., Sato, R., Takayanagi, M., Murayama, Y., Shiotani, M., and Kasai, Y.: The Level 2 research product algorithms for the Superconducting Submillimeter-Wave Limb-Emission Sounder (SMILES), Atmos. Meas. Tech., 4, 2105-2124, https://doi.org/10.5194/amt-4-2105-2011, 2011.

Baron, P., Murtagh, D. P., Urban, J., Sagawa, H., Ochiai, S., Kasai, Y., Kikuchi, K., Khosrawi, F., Körnich, H., Mizobuchi, S., Sagi, K., and Yasui, M.: Observation of horizontal winds in the middle-atmosphere between $30^{\circ} \mathrm{S}$ and $55^{\circ} \mathrm{N}$ during the northern winter 2009-2010, Atmos. Chem. Phys., 13, 6049-6064, https://doi.org/10.5194/acp-13-6049-2013, 2013.

Baron, P., Murtagh, D., Eriksson, P., Mendrok, J., Ochiai, S., Pérot, K., Sagawa, H., and Suzuki, M.: Simulation study for the Stratospheric Inferred Winds (SIW) sub-millimeter limb sounder, Atmos. Meas. Tech., 11, 4545-4566, https://doi.org/10.5194/amt11-4545-2018, 2018.
Clough, S. A., Kneizys, F. X., Shettle, E. P., and Anderson, G. P.: Atmospheric radiance and transmittance - FASCOD2, Sixth Conference on Atmospheric Radiation, Williamsburg, VA, 1316 May 1986, American Meteorological Society, Boston, MA, Extended Abstracts, A87-15076 04-47, 141-144, 1986.

Eriksson, P., Jiménez, C., and Buehler, S. A.: Qpack, a general tool for instrument simulation and retrieval work, J. Quant. Spectrosc. Ra., 91, 47-64, https://doi.org/10.1016/j.jqsrt.2004.05.050, 2005.

Eriksson, P., Ekström, M., Melsheimer, C., and Buehler, S. A.: Efficient forward modelling by matrix representation of sensor responses, Int. J. Remote Sens., 27, 1793-1808, https://doi.org/10.1080/01431160500447254, 2006.

Eriksson, P., Ekström, M., Rydberg, B., and Murtagh, D. P.: First Odin sub-mm retrievals in the tropical upper troposphere: ice cloud properties, Atmos. Chem. Phys., 7, 471-483, https://doi.org/10.5194/acp-7-471-2007, 2007.

Eriksson, P., Buehler, S. A., Davis, C. P., Emde, C., and Lemke, O.: ARTS, the atmospheric radiative transfer simulator, Version 2, J. Quant. Spectrosc. Ra., 112, 1551-1558, https://doi.org/10.1016/j.jqsrt.2011.03.001, 2011.

Johnson, D. G., Traub, W. A., Chance, K. V., Jucks, K. W., and Stachnik, R. A.: Estimating the abundance of $\mathrm{ClO}$ from simultaneous remote sensing measurements of $\mathrm{HO}_{2}, \mathrm{OH}$, and HOCl, Geophys. Res. Lett., 22, 1869-1871, https://doi.org/10.1029/95GL01249, 1995.

Kasai, Y., Sagawa, H., Kreyling, D., Dupuy, E., Baron, P., Mendrok, J., Suzuki, K., Sato, T. O., Nishibori, T., Mizobuchi, S., Kikuchi, K., Manabe, T., Ozeki, H., Sugita, T., Fujiwara, M., Irimajiri, Y., Walker, K. A., Bernath, P. F., Boone, C., Stiller, G., von Clarmann, T., Orphal, J., Urban, J., Murtagh, D., Llewellyn, E. J., Degenstein, D., Bourassa, A. E., Lloyd, N. D., Froidevaux, L., Birk, M., Wagner, G., Schreier, F., Xu, J., Vogt, P., Trautmann, T., and Yasui, M.: Validation of stratospheric and mesospheric ozone observed by SMILES from International Space Station, Atmos. Meas. Tech., 6, 2311-2338, https://doi.org/10.5194/amt6-2311-2013, 2013.

Kikuchi, K., Nishibori, T., Ochiai, S., Ozeki, H., Irimajiri, Y., Kasai, Y., Koike, M., Manabe, T., Mizukoshi, K., Murayama, Y., Nagahama, T., Sano, T., Sato, R., Seta, M., Takahashi, C., Takayanagi, M., Masuko, H., Inatani, J., Suzuki, M., and Shiotani, M.: Overview and early results of the Superconducting Submillimeter-Wave LimbEmission Sounder (SMILES), J. Geophys. Res., 115, D23306, https://doi.org/10.1029/2010JD014379, 2010.

Lambert, A., Read, W. G., Livesey, N. J., Santee, M. L., Manney, G. L., Froidevaux, L., Wu, D. L., Schwartz, M. J., Pumphrey, H. C., Jimenez, C., Nedoluha, G. E., Cofield, R. E., Cuddy, D. T., Daffer, W. H., Drouin, B. J., Fuller, R. A., Jarnot, R. F., Knosp, B. W., Pickett, H. M., Perun, V. S., Snyder, W. V., Stek, P. C., Thurstans, R. P., Wagner, P. A., Waters, J. W., Jucks, K. W., Toon, G. C., Stachnik, R. A., Bernath, P. F., Boone, C. D., Walker, K. A., Urban, J., Murtagh, D., Elkins, J. W., and Atlas, E.: Validation of the Aura Microwave Limb Sounder middle atmosphere water vapor and nitrous oxide measurements, J. Geophys. Res., 112, D24S36, https://doi.org/10.1029/2007JD008724, 2007.

Lary, D. J. and Aulov, O.: Space-based measurements of $\mathrm{HCl}$ : Intercomparisonand historical context, J. Geophys. Res., 113, D15S04, https://doi.org/10.1029/2007JD008715, 2008. 
Livesey, N. J. and Van Snyder, W.: EOS MLS Retrieval Processes Algorithm Theoretical Basis, Jet Propulsion Laboratory, California Institute of Technology, Pasadena, California, 91109-8099, Tech. Rep. JPL D-16159/CL \#04-2043, version 2.0, available at: https://mls.jpl.nasa.gov/data/eos_algorithm_atbd.pdf (last access: 26 March 2019), 2004.

Livesey, N. J., Filipiak, M. J., Froidevaux, L., Read, W. G., Lambet, A., Santee, M. L., Jiang, J. H., Pumphrey, H. C., Waters, J. W., Cofield, R. E., Cuddy, D. T., Daffer, W. H., Drouin, B. J., Fuller, R. A., Jarnot, R. F., Jiang, Y. B., Knosp, B. W., Li, Q. B., Perun, V. S., Schwartz, M. J., Snyder, W. V., Stek, P. C., Thurstans, R. P., Wagner, P. A., Avery, M., Browell, E. V., Cammas, J. P., Christensen, L. E., Diskin, G. S., Gao, R. S., Jost, H. J., Loewenstein, M., Lopez, J. D., Nedelec, P., Osterman, G. B., Sachse, G. W., and Webster, C. R.: Validation of Aura Microwave Limb Sounder $\mathrm{O}_{3}$ and $\mathrm{CO}$ observations in the upper troposphere and lower stratosphere, J. Geophys. Res., 113, D15S02, https://doi.org/10.1029/2007JD008805, 2008.

Livesey, N. J., Logan, J. A., Santee, M. L., Waters, J. W., Doherty, R. M., Read, W. G., Froidevaux, L., and Jiang, J. H.: Interrelated variations of $\mathrm{O}_{3}, \mathrm{CO}$ and deep convection in the tropical/subtropical upper troposphere observed by the Aura Microwave Limb Sounder (MLS) during 2004-2011, Atmos. Chem. Phys., 13, 579-598, https://doi.org/10.5194/acp-13-5792013, 2013.

Marks, C. J. and Rodgers, C. D.: A retrieval method for atmospheric composition from limb emission measurements, J. Geophys. Res., 98, 14939-14953, https://doi.org/10.1029/93JD01195, 1993.

Mätzler, C.: Thermal Microwave Radiation: Applications for Remote Sensing, Iee Electromagnetic Waves Series 52, 2006.

Millán, L., Livesey, N., Read, W., Froidevaux, L., Kinnison, D., Harwood, R., MacKenzie, I. A., and Chipperfield, M. P.: New Aura Microwave Limb Sounder observations of BrO and implications for $\mathrm{Br}_{\mathrm{y}}$, Atmos. Meas. Tech., 5, 1741-1751, https://doi.org/10.5194/amt-5-1741-2012, 2012.

Millán, L., Wang, S., Livesey, N., Kinnison, D., Sagawa, H., and Kasai, Y.: Stratospheric and mesospheric $\mathrm{HO}_{2}$ observations from the Aura Microwave Limb Sounder, Atmos. Chem. Phys., 15, 2889-2902, https://doi.org/10.5194/acp-15-2889-2015, 2015.

Millan, L., Livesey, N., and Read, W.: MLS/Aura Level 3 Bromine Monoxide (BrO) Daily 10degrees Lat Zonal Mean V004, Greenbelt, MD, USA, Goddard Earth Sciences Data and Information Services Center (GES DISC), https://doi.org/10.5067/Aura/MLS/DATA3020, 2016.

Murtagh, D., Frisk, U., Merino, F., Ridal, M., Jonsson, A., Stegman, J., Witt, G., Eriksson, P., Jimenez, C., Mégie, G., de la Nöe, J., Ricaud, P., Baron, P., Pardo, J., Hauchcorne, A., Llewellyn, E., Degenstein, D., Gattinger, R., Lloyd, N., Evans, W., McDade, I., Haley, C., Sioris, C., von Savigny, C., Solheim, B., McConnell, J., Strong, K., Richardson, E., Leppelmeier, G., Kyrola, E., Auvinen, H., and Oikarinen, L.: An overview of the Odin atmospheric mission, Can. J. Phys., 80, 309-319, https://doi.org/10.1139/P01157, 2002.

NASA Jet Propulsion Laboratory (JPL): JPL Molecular Spectroscopy Catalogue, available at: https://spec.jpl.nasa.gov/, last access: 21 February 2019

Ochiai, S., Baron, P., Nishibori, T., Irimajiri, Y., Uzawa, Y., Manabe, T., Maezawa, H., Mizuno, A., Nagahama, T., Sagawa, H.,
Suzuki, M., and Shiotani, M.: SMILES-2 Mission for Temperature, Wind, and Composition in the Whole Atmosphere, SOLA, 13A, 13-18, https://doi.org/10.2151/sola.13A-003, 2017.

Perrin, A., Puzzarini. C., Colmont, J.-M., Verdes, C., Wlodarczak, G., Cazzoli, G., Buehler, S., Flaud, J.-M., and Demaison, J.: Molecular Line Parameters for the "MASTER" (Millimeter Wave Acquisitions for Stratosphere/Troposphere Exchange Research) Database, J. Atmos. Chem., 51, 161-205, https://doi.org/10.1007/s10874-005-7185-9, 2005.

Pickett, H. M., Poynter, R. L., Cohen, E. A., Delitsky, M. L., Pearson, J. C., and Müller, H. S. P.: Submillimeter, millimeter, and microwave spectral line catalog, J. Quant. Spectrosc. Ra., 60, 883-890, https://doi.org/10.1016/S0022-4073(98)00091-0, 1998.

Pumphrey, H. C., Santee, M. L., Livesey, N. J., Schwartz, M. J., and Read, W. G.: Microwave Limb Sounder observations of biomass-burning products from the Australian bush fires of February 2009, Atmos. Chem. Phys., 11, 6285-6296, https://doi.org/10.5194/acp-11-6285-2011, 2011.

Pumphrey, H. C., Read, W. G., Livesey, N. J., and Yang, K.: Observations of volcanic $\mathrm{SO}_{2}$ from MLS on Aura, Atmos. Meas. Tech., 8, 195-209, https://doi.org/10.5194/amt-8-195-2015, 2015.

Rodgers, C. D.: Inverse Methods for Atmospheric Sounding: Theory and Practice, World Scientific, Singapore, 2000.

Rothman, L. S., Gordon, I. E., Babikov, Y., Barbe, A., Benner, D. C., Bernath, P. F., Birk, M., Bizzocchi, L., Boudon,V., Brown, L. R., Campargue, A., Chance, K., Cohen, E. A., Coudert, L. H., Devi, V. M., Drouin, B. J., Fayt, A., Flaud,J.-M., Gamache, R. R., Harrison, J. J., Hartmann, J. -M., Hill, C., Hodges, J. T., Jacquemart, D., Jolly, A., Lamouroux, J., Le Roy, R. J., Li, G., Long, D. A., Lyulin, O. M., Mackie, C. J., Massie, S. T., Mikhailenko, S., Müller, H. S. P., Nau-menko, O. V., Nikitin, A. V., Orphal, J., Perevalov, V., Per-rin, A., Polovtseva, E. R., Richard, C., Smith, M. A. H., Starikova, E., Sung, K., Tashkun, S., Tennyson, J., Toon, G. C., Tyuterev, V. G., and Wagner, G.: The HITRAN2012 molecular spectroscopic database, J. Quant. Spectrosc. Ra., 130, 4-50, https://doi.org/10.1016/j.jqsrt.2013.07.002, 2013.

Santee, M. L., Lambert, A., Read, W. G., Livesey, N. J., Manney, G. L., Cofield, R. E., Cuddy, D. T., Daffer, W. H., Drouin, B. J., Froidevaux, L., Fuller, R. A., Jarnot, R. F., Knosp, B. W., Perun, V. S., Snyder, W. V., Stek, P. C., Thurstans, R. P., Wagner, P. A., Waters, J. W., Connor, B., Urban, J., Murtagh, D., Ricaud, P., Barrett, B., Kleinböhl, A., Kuttippurath, J., Küllmann, H., von Hobe, M., Toon, G. C., and Stachnik, R. A.: Validation of the Aura Microwave Limb Sounder ClO measurements, J. Geophys. Res., 113, D15S22, https://doi.org/10.1029/2007JD008762, 2008.

Sato, T. O., Sagawa, H., Kreyling, D., Manabe, T., Ochiai, S., Kikuchi, K., Baron, P., Mendrok, J., Urban, J., Murtagh, D., Yasui, M., and Kasai, Y.: Strato-mesospheric ClO observations by SMILES: error analysis and diurnal variation, Atmos. Meas. Tech., 5, 2809-2825, https://doi.org/10.5194/amt-5-2809-2012, 2012.

Schwartz, M. J., Read, W. G., Snyder, W. V.: EOS MLS forward model polarized radiative transfer for Zeemansplit oxygen, IEEE T. Geosci. Remote, 44, 1182-1191, https://doi.org/10.1109/TGRS.2005.862267, 2006.

Suzuki, M., Manago, N., Ozeki, H., Ochiai, S., and Baron, P.: Sensitivity study of SMILES-2 for chemical species, in: 
Proc. SPIE 9639, Sensors, Systems, and Next-Generation Satellites XIX, Toulouse, France, 16 October 2015, 96390M, https://doi.org/10.1117/12.2194832, 2015.

Swadley, S. D., Poe, G. A., Bell, W., Hong, Y., Kunkee, D. B., McDermid, I. S., and Leblanc, T.: Analysis and Characterization of the SSMIS Upper Atmosphere Sounding Channel Measurements, IEEE T. Geosci. Remote, 46, 962-983, https://doi.org/10.1109/TGRS.2008.916980, 2008.

Takahashi, C., Ochiai, S., and Suzuki, M.: Operational retrieval algorithms for JEM/SMILES level 2 data processing system, J. Quant. Spectrosc. Ra., 111, 160-173, https://doi.org/10.1016/j.jqsrt.2009.06.005, 2010.

Takahashi, C., Suzuki, M., Mitsuda, C., Ochiai, S., Manago, N., Hayashi, H., Iwata, Y., Imai, K., Sano, T., Takayanagi, M., and Shiotani, M.: Capability for ozone high-precision retrieval on JEM/SMILES observation, Adv. Space Res., 48, 1076-1085, https://doi.org/10.1016/j.asr.2011.04.038, 2011.

University of Hamburg and Chalmers University of Technology: Qpack2, available at: http://www.radiativetransfer.org/tools/, last access: 15 December 2017a.

University of Hamburg and Chalmers University of Technology: The Atmospheric Radiative Transfer Simulator, available at: http://www.radiativetransfer.org/getarts/, last access: 15 December $2017 \mathrm{~b}$.

Urban, J.: Optimal sub-millimeter bands for passive limb observations of stratospheric $\mathrm{HBr}, \mathrm{BrO}, \mathrm{HOCl}$, and $\mathrm{HO}_{2}$ from space, J. Quant. Spectrosc. Ra., 76, 145-178, https://doi.org/10.1016/s0022-4073(02)00051-1, 2003.

Urban, J., Baron, P., Lautié, N., Schneider, N., Dassas, K., Ricaud, P., and De la Nöe, J.: Moliere (v5): a versatile forwardand inversion model for the millimeter and sub-millimeter wavelength range, J. Quant. Spectrosc. Ra., 83, 529-554, https://doi.org/10.1016/S0022-4073(03)00104-3, 2004.

Urban, J., Lautié, N., Le Flochmoën, E., Jiménez, C., Eriksson, P., de la Nöe, J., Dupuy, E., Ekström, M., El Amraoui, L., Frisk, U., Murtagh, D., Olberg, M., and Ricaud, P.: Odin/SMR limb observations of stratospheric trace gases: Level 2 processing of $\mathrm{ClO}, \mathrm{N}_{2} \mathrm{O}, \mathrm{HNO}_{3}$, and $\mathrm{O}_{3}$, J. Geophys. Res., 110, D14307, https://doi.org/10.1029/2004JD005741, 2005.

Waters, J. W., Froidevaux, L., Read, W. G., Manney, G. L., Elson, L. S., Flower, D. A., Jarnot, R. F., and Harwood, R. S.: Stratospheric $\mathrm{ClO}$ and ozone from the Microwave Limb Sounder on the Upper Atmosphere Research Satellite, Nature, 362, 597-602, https://doi.org/10.1038/362597a0, 1993.
Waters, J. W., Read, W. G., Froidevaux, L., Jarnot, R. F., Cofield, R. E., Flower, D. A., Lau, G. K., Pickett, H. M., Santee, M. L., Wu, D. L., Boyles, M. A., Burke, J. R., Lay, R. R., Loo, M. S., Livesey, N. J., Lungu, T. A., Manney, G. L., Nakamura, L. L., Perun, V. S., Ridenoure, B. P., Shippony, Z., Siegel, P. H., and Thurstans, R. P.: The UARS and EOS microwave limb sounder experiments, J. Atmos. Sci., 56, 194-218, https://doi.org/10.1175/15200469(1999)056<0194:TUAEML>2.0.CO;2, 1999.

Waters, J. W., Froidevaux, L., Jarnot, R. F., Read, W. G., Pickett, H. M., Harwood, R. S., Cofield, R. E., Filipiak, M. J., Flower, D. A., Livesey, N. J., Manney, G. L., Pumphrey, H. C., Santee, M. L., Siegel, P. H., and Wu, D. L.: An Overview of the EOS MLS Experiment., Tech. Rep. JPL D-15745 / CL\# 042323, Jet Propulsion Laboratory, California Institute of Technology, Pasadena, California, 91109-8099, Version 2.0, available at: https://mls.jpl.nasa.gov/data/eos_overview_atbd.pdf (last access: 26 March 2019), 2004.

Waters, J. W., Froidevaux, L., Harwood, R. S., Jarnot, R. F., Pickett, H. M., Read, W. G., Siegel, P. H., Cofield, R. E., Filipiak, M. J., Flower, D. A., Holden, J. R., Lau, G. K., Livesey, N. J., Manney, G. L., Pumphrey, H. C., Santee, M. L., Wu, D. L., Cuddy, D. T., Lay, R. R., Loo, M. S., Perun, V. S., Schwartz, M. J., Stek, P. C., Thurstans, R. P., Boyles, M. A., Chandra, K. M., Chavez, M. C., Chen, G.-S., Chudasama, B. V., Dodge, R., Fuller, R. A., Girard, M. A., Jiang, J. H., Jiang, Y., Knosp, B. W., LaBelle, R. C., Lam, J. C., Lee, K. A., Miller, D., Oswald, J. E., Patel, N. C., Pukala, D. M., Quintero, O., Scaff, D. M., Snyder, W. V., Tope, M. C., Wagner, P. A., and Walch, M. J.: The Earth Observing System Microwave Limb Sounder (EOS MLS) on the Aura Satellite, IEEE T. Geosci. Remote, 44, 1075-1092, https://doi.org/10.1109/TGRS.2006.873771, 2006.

Wu, D. L., Schwartz, M. J., Waters, J. W., Limpasuvan, V., Wu, Q., and Killeen, T. L.: Mesospheric doppler wind measurements from Aura Microwave Limb Sounder (MLS), Adv. Space Res., 42, 1246-1252, https://doi.org/10.1016/j.asr.2007.06.014, 2008. 